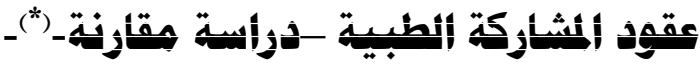

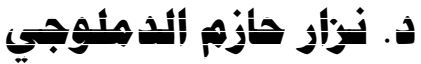

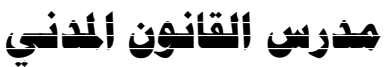

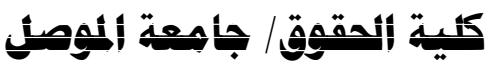

كان من نتاج الفكر البشري ظهور مهنة الطب تلك المهنة التي تعد من أنبل المهن

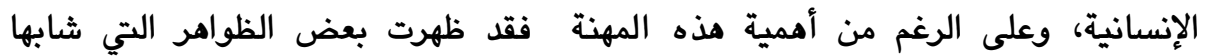

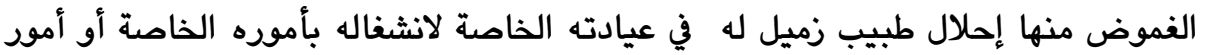
تخص المهنة، هذا الحلول الذي يحتاج الى تفويض من قبل الطبيب صاحب العيادة الخاصة

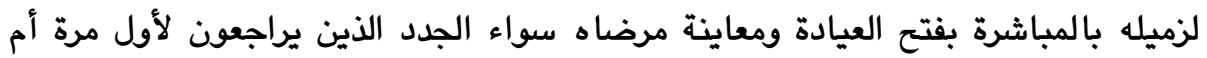

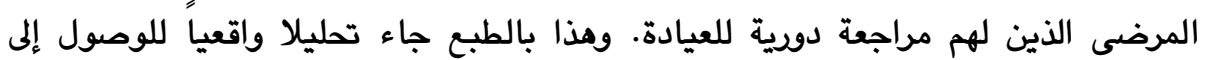
التكييف القانوني لهذه الحالة وذلك لوجود قصور تشريعي بل وفقهي في معالجة مثل هذه الحالات، ولعل غياب التنظيم القانوني يعود لعدم توقع ظهور مثل هذا النوع من العقود، مما

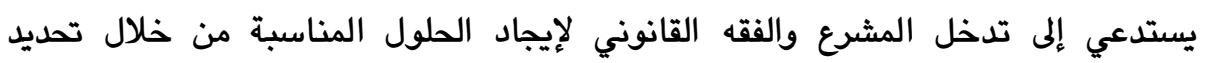
التزامات الأطباء الذين يمثلون أطراف العقد ومسؤوليتهم إذا ما خالفوا القواعد القانونية

\section{Abstract $\square$}

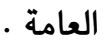

as a result of humanity needs and thoughts, medicine as profession have been found, which is considered as one of the most nobel professions. despite of the importance of medicine, some of confusing phenomena have been appeared. one of these phenomena is physician's allowance to other physician to inspect patients and prescribe medications in his own clinic and under his title. this type of situations require specific authorization from original physician to the other one. presence of such circumstances

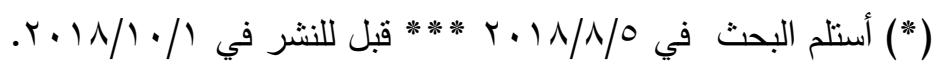


indicating legalization of some regulations and laws will find solutions for any problems that may initiate in the future. one of these regulations suggestions is a contract form contain all the terms and conditions that keep rights and duties for both parties, in addition, this contract should be supervised by Iraqi medical association.

\section{|}

نبدأ بحمد الله جلت قدرته وعظمته، على سابغ نعمته وفيض إحسانه، ونصلى

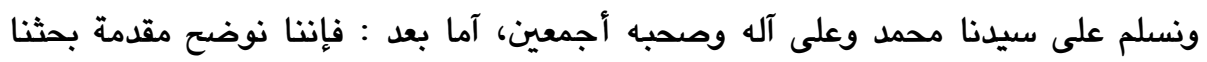

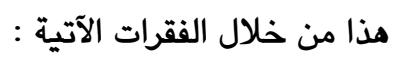
أولا: مدخل تعريفي بموضوع البحث :

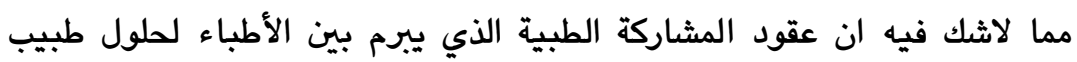

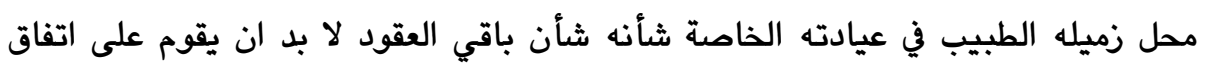

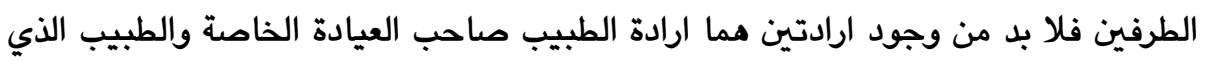

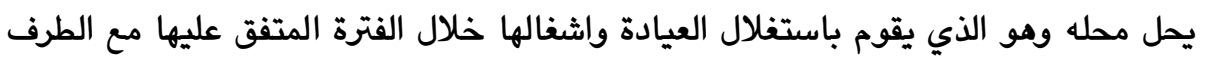
الاول ـ وهذا العقد له خصوصية معينة فهو يقوم على اساس الثقة المتبادلة بين الطرفين فلولا ثقة الطرف الاول (صاحب العيادة) بالطرف الثاني (الطبيب الذي يحل محله) ويخبرته وعلمه ودرايته بالعلوم الطبية ما كان هذا العقد لينعقد . فهذا النوع من العقود

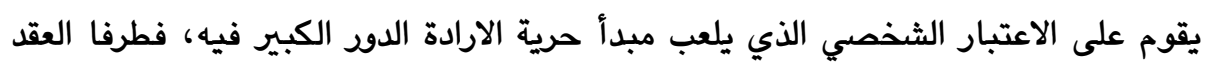

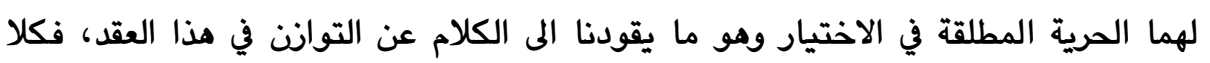

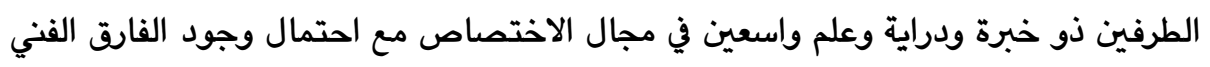
البسيط.

واذا كان الامر يبدو سهلاً للوهلة الاولى ولكن الامر ليس كذلك اذا ما تناولنا اثر هذا

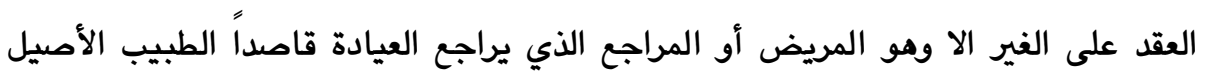

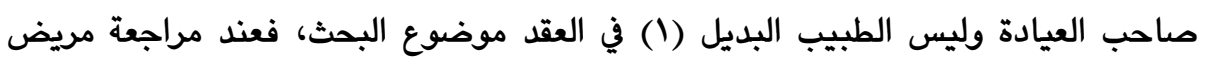

(1) يعرف الطبيب البديل ب" ذللك الطبيب الذي يخلف الطبيب المعالج بصفة مؤقتة في تتفيذ كل العلاج او في جزء منه بمفرده دون ان يكون الطبيب المعالج الى جانبه وهو

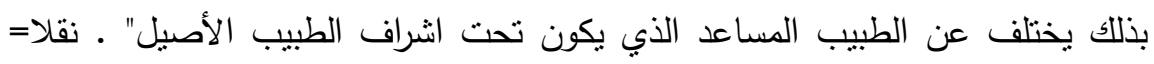


لعيادة طبيب مشهور ذي خبرة ومن ثم يتبين له بأن الطبيب المتواجد ليس بالطبيب المقصود او المراد، وان المتواجد في العيادة طبيب اخر حل محل الطبيب المشهور لفترة مؤقتة. فيكون المريض أو من يمثله بالخيار بين ان يكثف عليه ويعالجه الطبيب البديل ام لا. وقد نذهب الى ابعد من ذلك فقد يتفاجأ الأخير بأن الطبيب الذي كثف عليه ليس المطلوب الذي قصده، ويكون ذلك بسبب جهل المريض وعدم انتباهه لإعلان وضع في العيادة ولعدم معرفة المريض بشخص الطبيب الذي يقصده، فيكشف الطبيب البديل على المريض والاخير جاهل بالطبيب الذي يكثف عليه فيأخذ باستشارته الطبية ويستخدم العلاج الموصوف ويتفاجأ فيما بعد بأن الطبيب الذي كثف عليه ليس بالطبيب المقصود. من هذا المنطلق ثار موضوع البحث في ذهننا وطرح التساؤل عن الطبيعة القانونية لهذا النوع من العقود فهل مذا العقد يعد عقد ايجار ام عقد عمل ام عقد مشاركة ( يقوم بدفع الطبيب البديل للطبيب الأصيل نسبة من المبالغ التي يحصل عليها نتيجة لاستغلال العيادة ) وعن مسؤولية الطبيب البديل والطبيب الأصيل في حالة حصول الخطأ الطبي، وعن ضرورة تبصير المريض المراجع بأن الطبيب المتواجد ليس بالطبيب الأصيل . هذا ما سوف نحاول نبينه في بحثنا هذا .

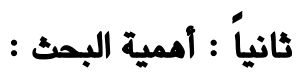

تبرز أهمية مذا البحث من خلال تسليط الضوء على حالة واقعية تسود المجتمع الا وهي حلول طبيب محل طبيب في عيادته الخاصة فعادة ما يكون الطبيب الذي حل هو اقل ثهرة من الطبيب الأصيل صاحب العيادة الخاصة، وهو يقودنا لتسليط الضوء على القصور التشريعي في موضوع حلول الأطباء محل بعضهم البعض في عياداتهم الخاصة وطبيعة الاتفاق بالحلول مذا، وما لهذا الحلول من تأثير على إرادة المريض المراجع لتلك العيادات، وفي عدم الوضوح الذي يشوب مسؤولية أولائك الأطباء في حالة حدوث الأخطاء

=عن: أيت مولود ذهبية، المسؤولية المدنية عن أخطاء الفريق الطبي، رسالة ماجستير،

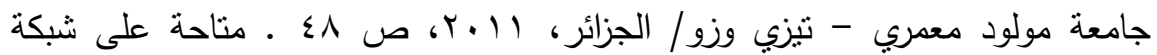
المعلومات العالمية . .http://www.droitetentreprise.com

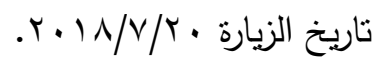


تتمثل فرضية البحث بوضع قواعد قانونية رصينة تبين طبيعة عقود المشاركة

الطبية بين الأطباء لحلول طبيب محل زميله في عيادته الخاصة من خلال الإفادة من التشريعات القانونية للدول التي عالجت الموضوع أو من خلال استعارة قوالب قانونية وصهر القواعد التقليدية فيها بما يتلاءم مع انتشار الحالة اخذين بنظر الاعتبار ان العلوم

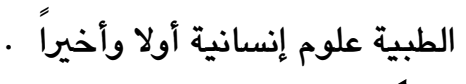

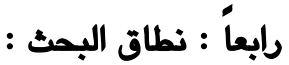

سيقتصر نطاق البحث على حالة حلول طبيب محل طبيب زميل له في عيادته الخاصة اثناء غيابه او انشغاله بأموره الخاصة او بأمور تخص المهنة كالمؤتمرات والندوات

خامساً : مشكلة البحث : وغيرها ان حلول طبيب محل زميل له في عيادته الخاصة محل نقاش في ظل القواعد القانونية الطبية، مما يدفعنا للتساؤل عن الطبيعة القانونية لهذا الحلول ومدى مسؤولية الطبيب الأصيل والبديل في حالة حصول الخطأ الطبي، فظلا عن غياب التنظيم القانوني المحكم مما يدفعنا المى المناداة للاستعارة بالقوالب القانونية التقليدية لمعالجة القصور

$$
\text { سادساً : منهي لهذه الحالات . }
$$

سيعتمد الباحث في هذه الدراسة على المنهج التحليلي والعملي التطبيقي وذلك من

خلال استقراء النصوص القانونية الخاصة بممارسة مهنة الطب .وسيعتمد الباحث المنهج المقارن اذ سيقارن بين قانون نقابة الأطباء العراقي بتحليله ومقارنته بالقوانين المقارنة مثل قانون الصحة العامة الفرنسي و مدونة الأخلاقيات الطبية الفرنسية، قانون ممارسة مهنة الطب المصري، الدستور الطبي الأردني/ واجبات الطبيب وآداب المهنة، قانون ممارسة مهنة الطب المغربي، وغيرها التشريعات ذات الاختصاص . سادساً : ميكلية البحث : مهارسية

سوف يتم تناول البحث من خلال الهيكلية التالية : المبحث الأول : التعريف بعقود المشاركة الطبية :

المطلب الأول : تعريف عقود المشاركة الطبية . 
المطلب الثاني : خصائص عقود المشاركة الطبية وتكييفها القانوني •

المبحث الثاني : أركان عقود المشاركة الطبية والآثار الناشئة عنها :

المطلب الأول : أركان عقود المشاركة الطبية .

المطلب الثاني : الآثار الناشئة عن عقود المشاركة الطبية .

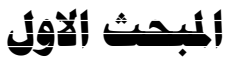

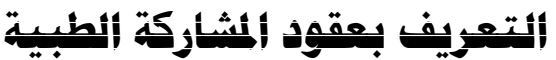

إن العقد في القوانين القديمة لم يكن يرد إلا على الأثياء المادية أما الحقوق والأموال المعنوية والمنافع (الإيجار، المقاولة، العمل) فلم يكن يعترف بصحة العقود الواردة عليها، ولكن بحدوث تطور الفكر القانوني وما وصلت إليه العقود بوصفه مصدراً رئيساً لإنشاء الحقوق والالتزامات أصبحت هذه العقود ترد على الحقوق والأموال المادية والمعنوية فضلا عن وردمها على المنافع والخدمات . مذا ما أوصلنا إلى القول بإمكانية وجود عقود ترد على الخدمات التي يكون فيها الدافع الرئيسي للتعاقد هو الحصول على خدمة معينة بالذات سواء أكانت هذه الخدمة تجارية ام علمية ام طبية، وهو ما سنحاول ان نبينه من خلال تقسيم هذا المبحث الى مطلبين نتناول في المطلب الأول تعريف عقود المشاركة الطبية أما المطلب الثاني فسوف نتناول فيه خصائص عقود المشاركة الطبية وتكييفها القانوني وكما يأتي :

\section{jexil thil}

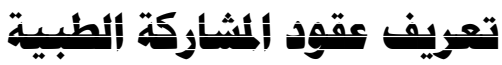

العقد لغة : نقيض الحل · والعقد يعني الإحكام والشد، فيقال عقد الحبل، نقيض

حله وعقد البيع أو اليمين احكمه، والعقد هو العهد فيقال تعاقد القوم أي تعامدوا"( والعقد اصطلاحاً: "ارتباط الإيجاب الصادر من احد العاقدين بقبول الآخر على

وجه يثبت أثره في المعقود عليه" (r).

(1) العلامة أبن منظور، لسان العرب، الجزء العاثر ، الطبعة الرابعة، دار صادر للطباعة

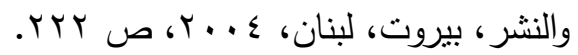

(Y) المادة رقم rV من القانون المدني العراقي رقم • ع لسنة 1901 ـ ـومن الملاحظ في هذا

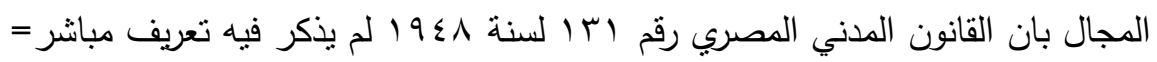


كما عرف بأنه "اتفاق يلتزم بمقتضاه شخص أو أشخاص في مواجهة شخص أو أشخاص آخرين إما بإعطاء شيء أو القيام بعمل أو الامتناع عن عمل" (1).

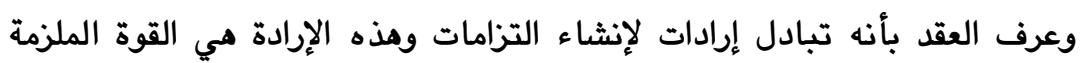
للعقد استنادا لمبدأ سلطان الإرادة(汭

والمشاركة لغة هو اسم مصدره شارك، ومشاركة في العمل هي المساهمة فيه . ومشارك فاعل شارك مشاركة، ويقال اشتركنا بمعنى تشاركنا واشترك الرجلان وتشاركا

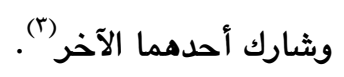

وعقود المشاركة الطبية تتم بين طرفين الأول منهما الطبيب صاحب العيادة الخاصة والثاني الطبيب الذي يحل محله ـ ويمقتضى هذا الاتفاق يكون الطرف الاول ملزم

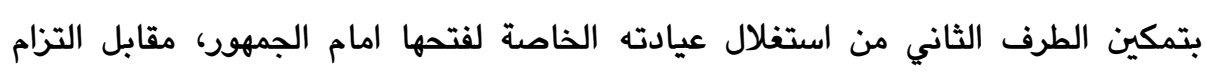

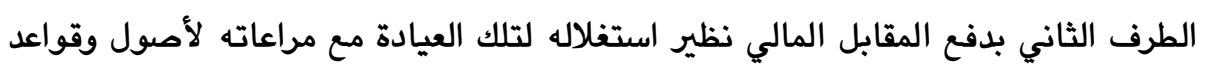

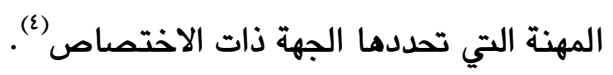

من هنا يمكننا ان نعرف عقود المشاركة الطبية بأنها (اتفاق بين طرفين يتمثل

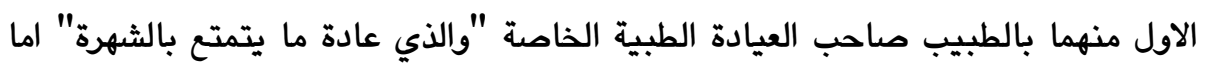

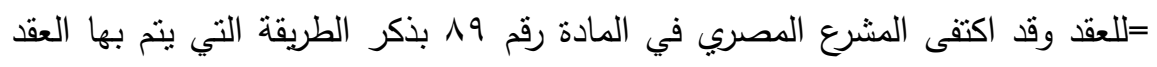

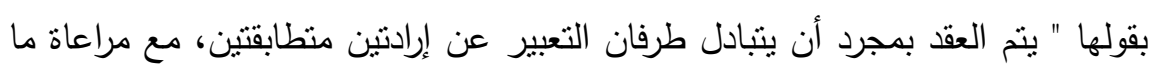
يقرره القانون فوق ذلك من أوضاع معينة لانعقاد العقد".

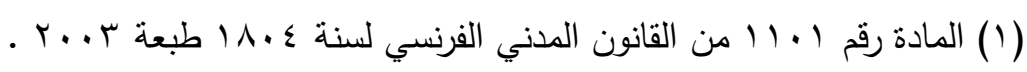

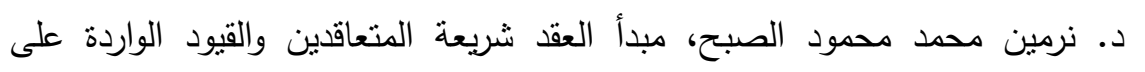

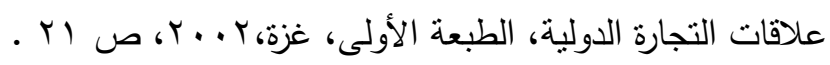

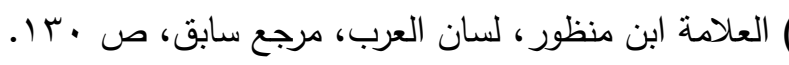

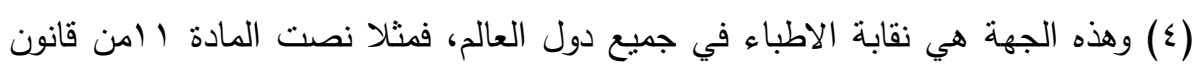

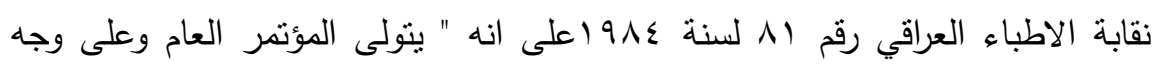

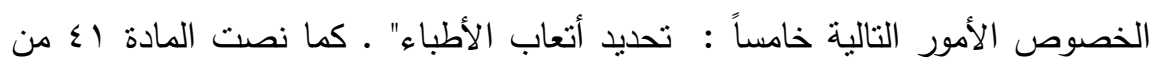

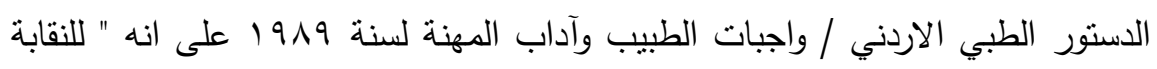

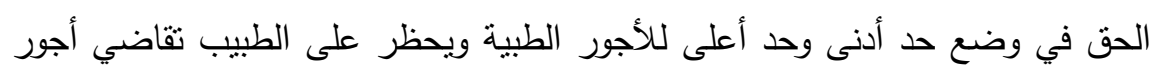

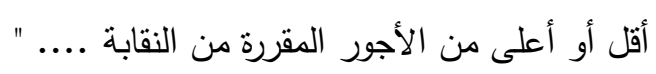


الطرف الثاني فيتمثل بالطبيب الذي يحل محله في تلك العيادة، ويتعهد الطرف الأول بمقتضى هذا الاتفاق بتمكين الطرف الثاني من استغلال عيادته الخاصة مقابل مبلغ مالي

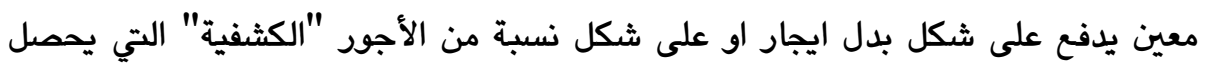
عليها من المراجعين). وقد اتجه الفقه والقضاء في الجزائر إلى الاعتراف بمشروعية اتفاقيات الحلول التي يبرمها الطبيب المعالج مع زميل له فيعهد للأخير بعلاج مرضى الطبيب الأصيل لمدة مؤقتة، وفقا لقواعد أخلاقيات مهنة الطب، التي تشترط أن يكون البديل على كفاءة وخبرة

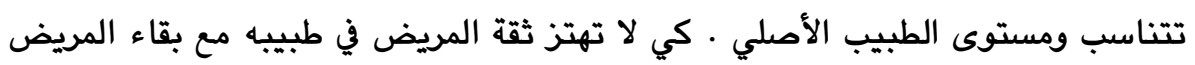

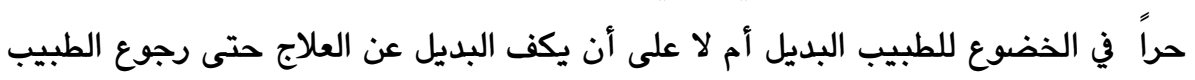

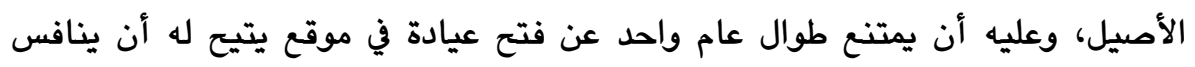

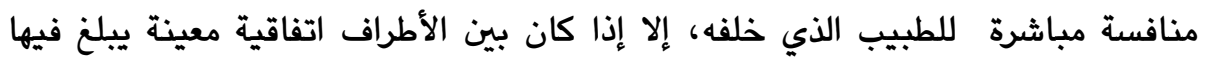
الفرع النظامي الجهوي • فقد تقتضي ظروف الطبيب المعالج، التوقف مؤقتا عن الاستمرار

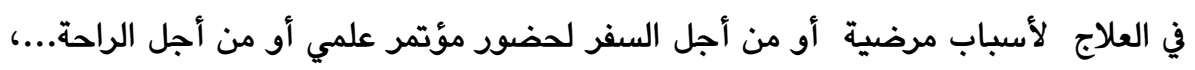
فيصبح من واجبه حينذاك إحضار من يحل محله طوال مدة غيابه . فإمكانية استبدال طبيب مكان طبيب آخر، هو ضمان لاستمرارية علاج المرضى في طور المعالجة، وضمان

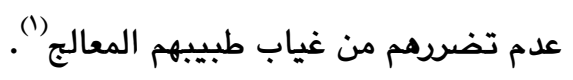
فيلجأ الاطباء من اصحاب العيادات الخاصة لأبرام هذا النوع من العقود عند سفرهم او لانشغالهم بأمورهم الخاصة، او لسبب مرض او عجز الاه من يصابون به ـ ـ وعلى الرغم

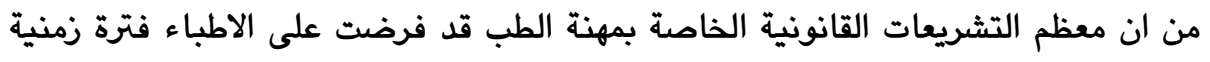
معينة لهذا الحلول، الا انه من الملاحظ وجود حالات يستمر فيها مذا الحلول لفترة تزيد

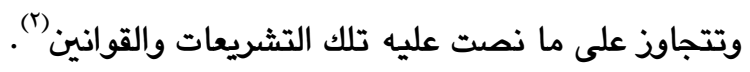

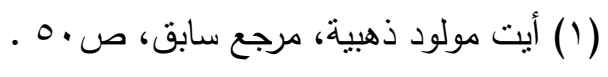

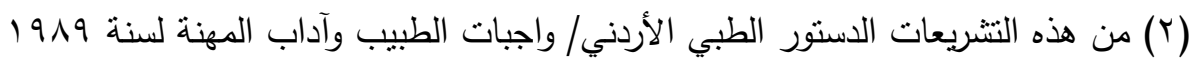

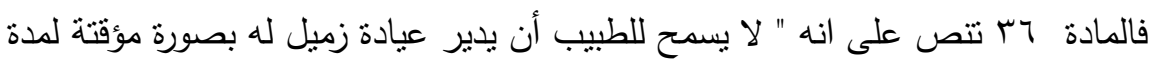

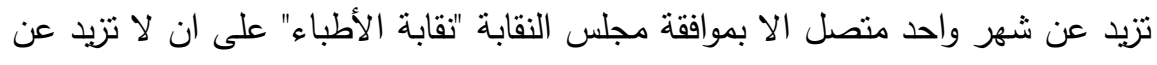

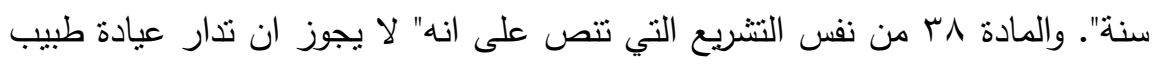

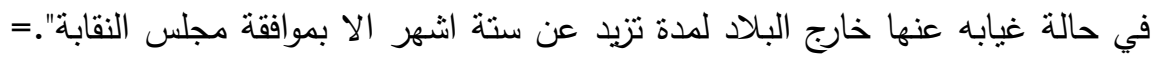


ولكن هذا الحلول له شروط معينة فقد اشترطت بعض القوانين الخاصة بممارسة

مهنة الطب الحصول على موافقات اصولية من الجهات الرقابية ذات الاختصاص فمثلا

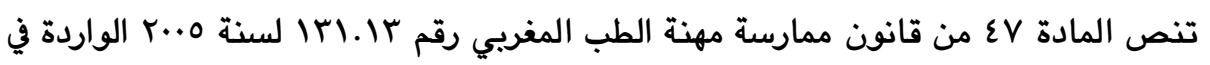

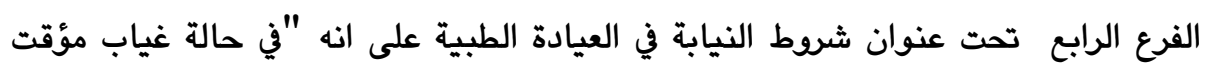
يمكن لطبيب أن يطلب من رئيس المجلس الجهوي الترخيص له بأن ينيب عنه في عيادته

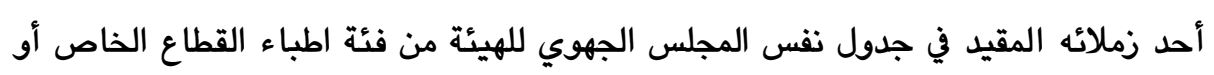

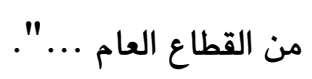

ونصت المادة حr من الدستور الطبي الاردني/ واجبات الطبيب وآداب المهنة

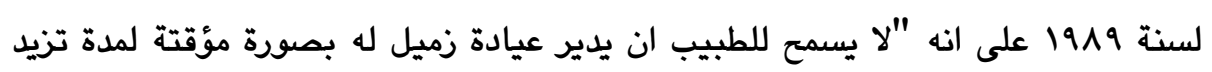

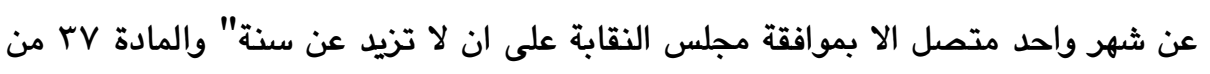
نفس الدستور على انه "لا يجوز للطبيب ان ينيب عنه بصورة مؤقتة لمراقبة ومعالجة

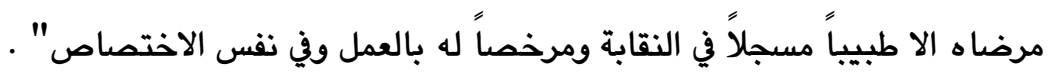

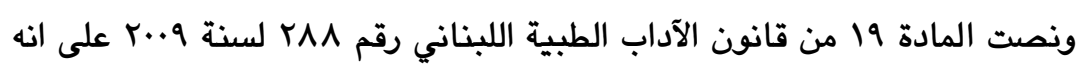

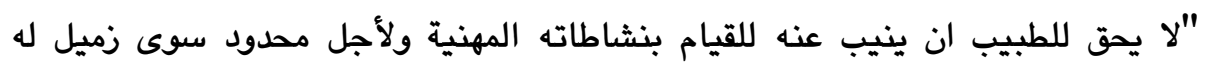

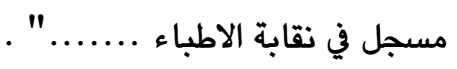
كما نصت المادة بr من قانون لائحة آداب وميثاق شرف مهنة الطب البشري

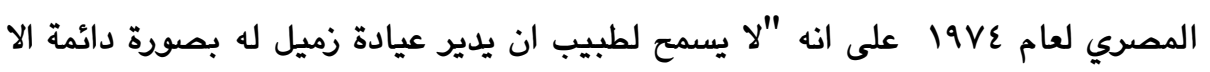

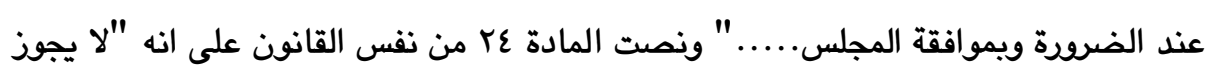

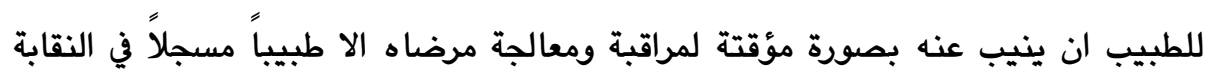
........ وكذلك الحال بالنسبة لقانون مزاولة مهنتي الطب البشري وطب وجراحة الأسنان

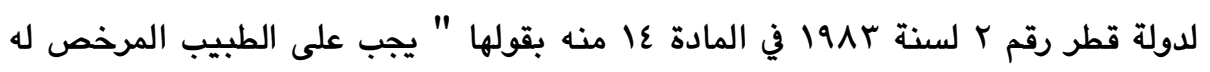

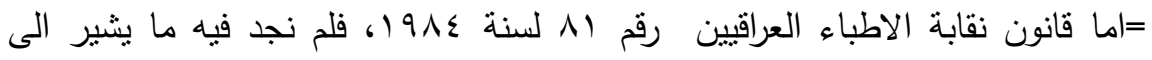
تحديد مدة معينة لحلول طبيب محل زميله في عيادته الخاصة فقط كانت هناللك انشارة

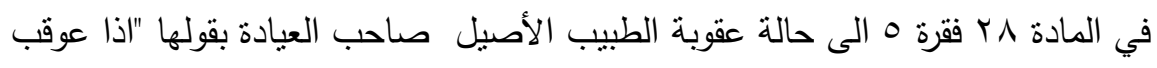
العضو بالمنع من مزاولة المهنة فلا يجوز ان يحل في عيادته زميل الميل اخر مدة المنع". 
بالعمل في القطاع الخاص إخطار الجهة المختصة بكتاب موصى عليه عند مغادرته البلاد

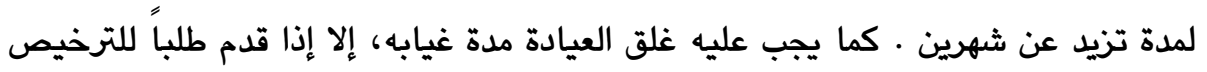

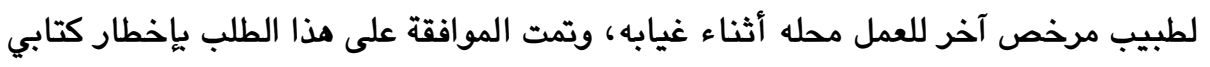

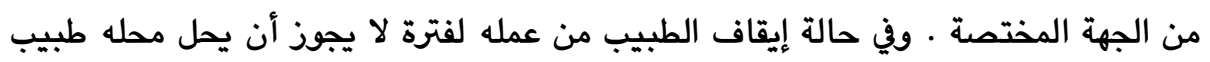

$$
\text { آخر مدة الإيقاف، وتغلق العيادة". }
$$

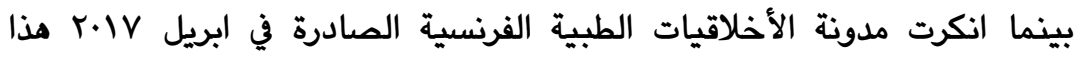

الحلول كقاعدة عامة وحصرته في حالة الوفاة والمرض الذي وصفته بالخطير فنصت المادة

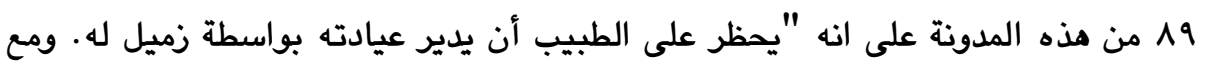

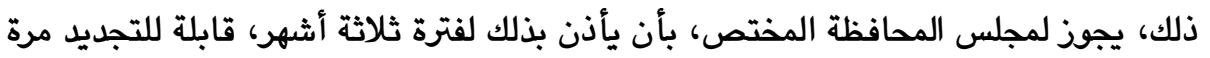

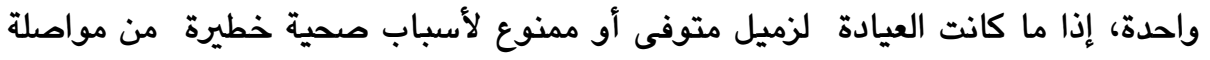
نشاطه" اما بالنسبة لقانون نقابة الاطباء العراقيين رقم ای لسنة ع191 فلم ترد اية اشارة على الشروط المفروضة على هذا الحلول ولا حتى على المدة الزمنية لهذا الحلول واكتفى

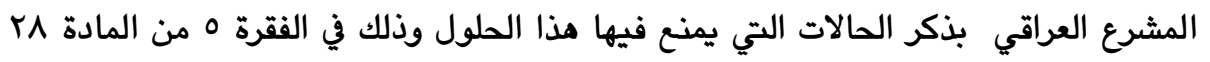
من هذا القانون بقولها "اذا عوقب العضو بالمنع من مزاولة المهنة فلا يجوز ان يحل في

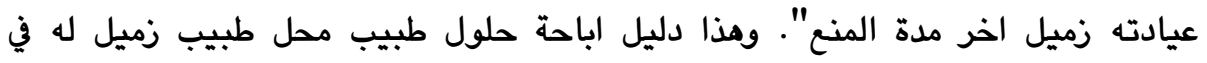

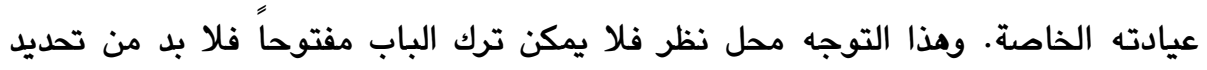
حالات معينة يسمح فيها للطبيب ان يحل الطبيب محل زميله في عيادته الخاصة كالإيفاد لأغراض علمية وغيرها من حالات الضرورة مع تحديد فترة زمنية معينة لهذا الحلول.

\section{|}

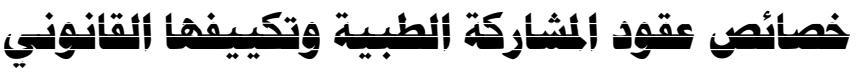

إن عقود المشاركة الطبية شأنها شأن باقي العقود لها خصائص تميزها، فهي

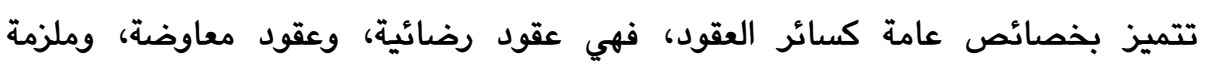
للجانبين وعقود مستمرة.

عليه ولما تقدم سوف نقسم هذا المطلب على فرعين نخصص الفرع الأول لبيان

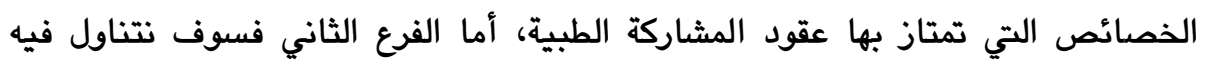
التكييف القانوني لعقود المشاركة الطبية وعلى النحو الآتي: 


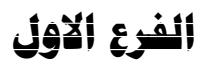 \\ خصائمي عقد أشئركة أنطبية}

تمتاز عقود المشاركة الطبية بأنها من العقود غير المسماة كما تمتاز بأنها من

العقود الرضائية التي يكفي لانعقادها مجرد تراضي الطرفين دون الحاجة إلى اتخاذ العقد لشكل معين، كما تمتاز بأنها من عقود المعاوضة التي تنشئ التزامات متقابلة على طرفيها، وهي من العقود المستمرة. عليه سوف نتناول هذا المطلب وفق التقسيم التالي أولاً: عقود المشاركة الطبية باعتبارها عقوداً رضائية ثانياً: عقود المشاركة الطبية عقود معاوضة وعقود ملزمة للجانبين اما ثالثاً : فسوف نتكلم على عقود المشاركة الطبية باعتبارها عقوداً

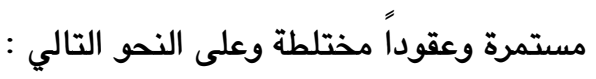
أولاً : عقود المشاركة الطبية عقود رضائية

تعتبر عقود المشاركة الطبية من العقود الرضائية التي يكفي لانعقادها توافق الارادتين، ولم يشترط القانون شكلاً معيناً لهذا الاتفاق . فيكفي في مذا النوع من العقود مجرد ارتباط الإيجاب الصادر احد الطرفين بالقبول الصادر من الطرف الاخر في العقد . فهذا العقد ينعقد لمجرد قبول الطرف الثاني للإيجاب الصادر من الطرف الأول (1). كما تنقسم العقود من حيث تنظيمها التشريعي إلى عقود مسماة تكفل المشرع بتنظيمها وخصص لها أسماً معيناً مثل "البيع والإيجار" وذلك لشيوعها في التعامل بين تين الناس، وعقود أخرى لم يقم المشرع بتنظيمها ولم يحدد لها اسماً معيناً ولم يرتب لها أحكاما خاصة تعرف بالعقود غير المسماة(؟). وهذه العقود تخضع في تنظيمها وآثارها

(1) د. حسن علي الذنون، النظرية العامة للالتزام، الجزء الأول، مصادر الالتزام، بغداد، EY ص ( $19 \vee 7$

(Y) لقد عرف الفقه الإسلامي العقود المسماة وهي خمسة وعثرون عقداً تضمنت مجلة الأحكام العدلية ثمانية عشر عقداً منها وهي ( البيع، والإجارة، والكفالة، والحوالة، والرهن، وبيع الوفاء، ....... الخ )، د. مصطفي احمد الزرقا، المدخل الفقهي العام، الجزء الأول،

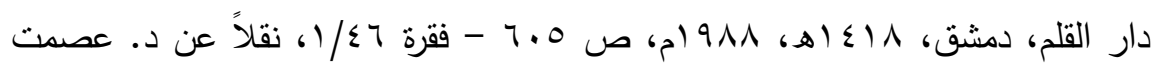
عبد المجيد بكر، نظرية العقد في الفقه الإسلامي " دراسة مقارنة مع الفقه القانوني

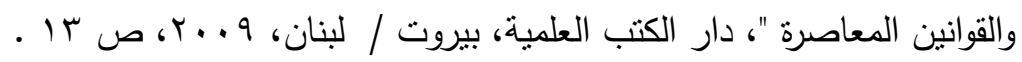


للقواعد العامة التي تحكم مختلف العقود (1) فالعقود تتطور من زمن إلى أخر بحسب ما يألفه الناس من تعامل وما تفرضه الحاجة والتطور في شتى الميادين القانونية والعلمية، والإنسان حر في إبرام ما يشاء من العقود بشرط ان تكون مذه العقود غير مخالفة للقانون

$$
\text { والنظام العام والآداب العامة . }
$$

ثانياً : عقود المشاركة الطبية عقود معاوضة ملزمة للجانبين

وتتصف عقود المشاركة الطبية بأنها من عقود المعاوضة، تلك العقود الذي يأخذ

فيه كلا المتعاقدين مقابلاً لما أعطاه ـ فهي عقود معاوضة بالنسبة للطبيب صاحب العيادة الخاصة لأنه يأخذ مقابلاً لما أعطاه كبدل ايجار او نسبة من الاجور التي يحصل عليها الطبيب البديل , ويالعكس فأن الطبيب البديل يتمكن من استخدام العيادة كمقابل للذي - يعطيه

فضلا عن ما تقدم تعد عقود المشاركة الطبية من العقود الملزمة للجانبين والتي

تلقي على عاتق كل طرف التزامات متقابلة، فالطبيب الأصيل صاحب العيادة ملزم بتمكين البديل من استخدام عيادته الخاصة، ويالمقابل على الطبيب البديل باعتباره الطرف الثاني في العقد ابتداء تسديد المقابل المالي نظير استفادته من العيادة ومن ثم الالتزام بالاستخدام الأمثل لهذه العيادة من خلال العمل بمهنية بما يتناسب واخلاق مهنة الطب.

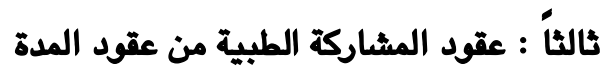
وتعد عقود المشاركة الطبية من العقود المستمرة أو ما تعرف بعقود المدة التي

يكون الزمن عنصراً جومرياً فيها بحيث يكون المقياس الذي يقدر به محل العقد (r). فتنص المادة حس من الدستور الطبي الاردني لسنة 9191اعلى انه "لا يسمح للطبيب أن يدير عيادة زميل له بصورة مؤقتة لمدة تزيد عن شهر واحد متصل إلا بموافقة

(1) تتص الفقرة الأولى من المادة رقم VT من القانون المدني العراقي على انه (تسري على العقود المسماة منها وغير المسماة القواعد العامة التي بشتمل عليها هذا الفصل)، كما نصت الأعمال التحضيرية الثانية للمشروع التمهيدي للتقنين المدني المصري في المادة رقم وY ا على أن (ا ـ تسري على العقود المسماة منها وغير المسماة القواعد العامة التي

بشتمل عليها هذا الفصل).

(ץ) د. سعدون العامري، الوجيز في شرح العقود المسماة، الجزء الأول، البيع والإيجار،

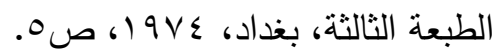


مجلس النقابة على أن لا تزيد عن سنة" كما تنص المادة مب منه كذلك على انه "لا يجوز

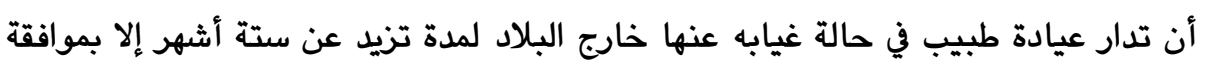

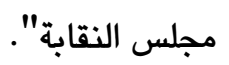

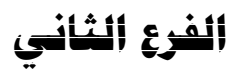

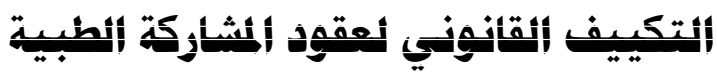

إن تحديد طبيعة العلاقة القانونية وردها إلى نظام قانوني معين تسمى التكييف،

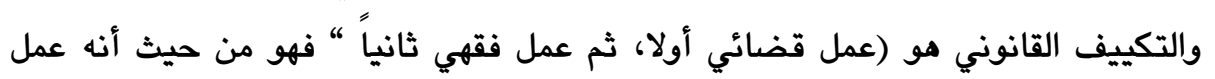

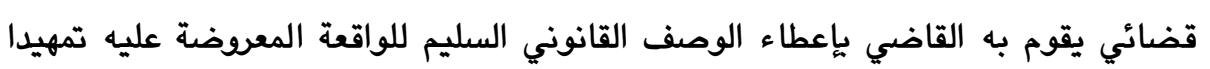
لتطبيق الحكم القانوني الملائم عليها “ كما أنه عمل فقهي يقوم به الفقيه بتصنيف الوقائع

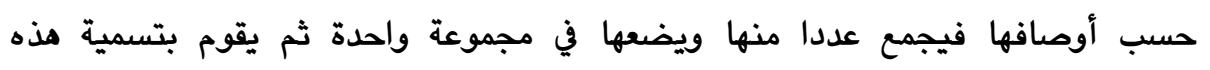

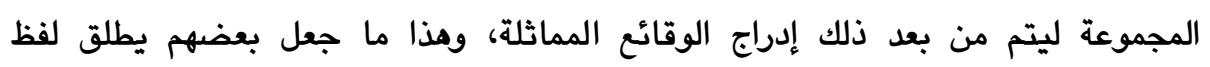

$$
\text { التصنيف على التكييف) (1) }
$$

وكلمة تكييف على ونن تفعيل أي أن الذي يقوم بهذا الفعل هو الذي يجعل

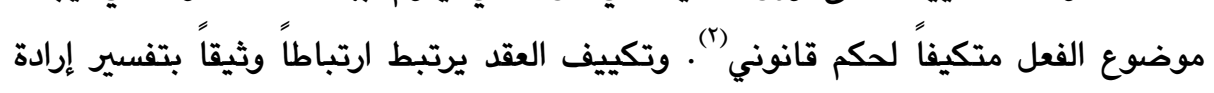

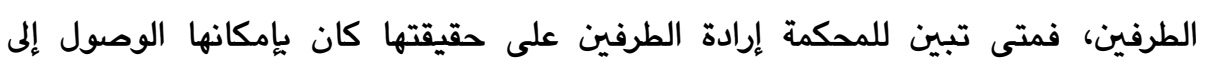
التكييف القانوني الصحيح للعقد من غير التقيد بتكييف العاقدين له.

د. سامي بديع منصور، د. عكاشة عبد العال، القانون الدولي الخاص، الدار الجامعية،

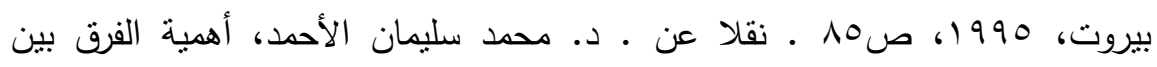
التكييف القانوني والطبيعة القانونية في تحديد نطاق تطبيق القانون المختص، بحث

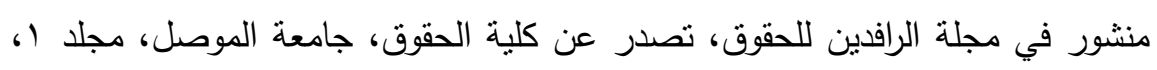

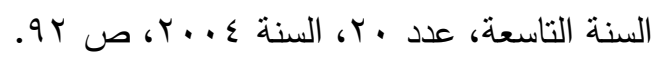

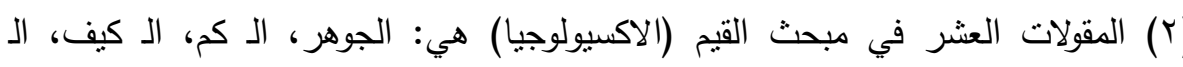

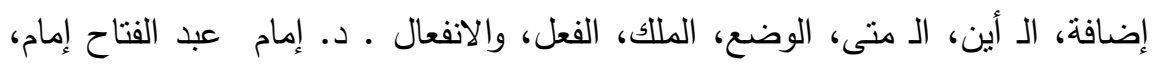

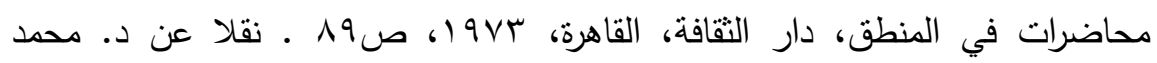

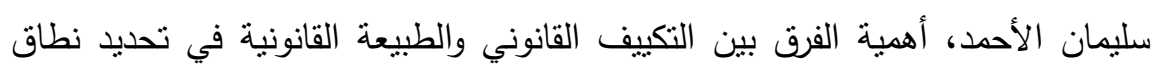

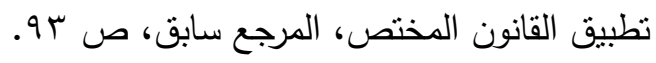


وحيث ان عقود المشاركة الطبية من العقود الحديثة النشأة سوف نحاول الوصول

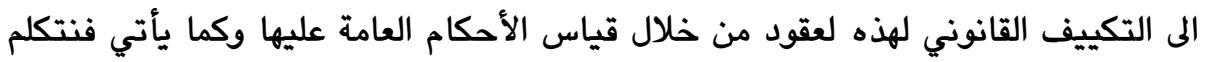

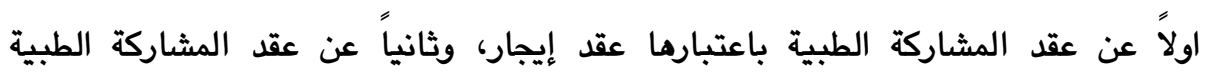

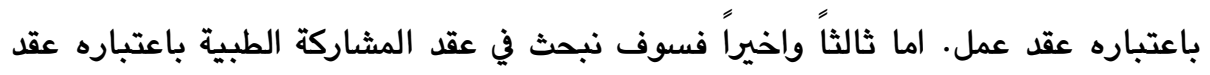

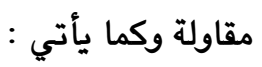
أولاً: عقد المشاركة الطبية باعتباره عقد إيجار عرف المشرع العراقي عقد الإيجار بأنه "تمليك منفعة معلومة بعوض معلوم لمدة إيجار معلومة ويه يلتزم المؤجر أن يمكن المستأجر من الانتفاع بالمأجور" (1). ويمقتضى عقد الإيجار يلتزم المؤجر بتمكين المستأجر من الانتفاع بالشيء

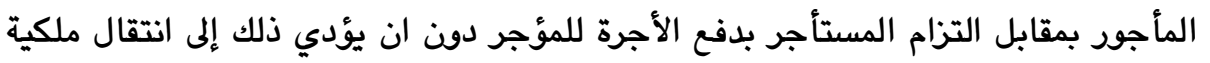

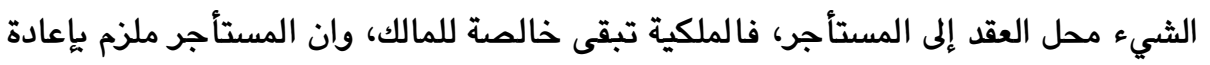

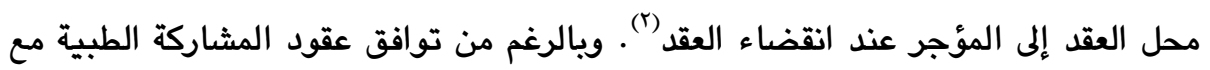

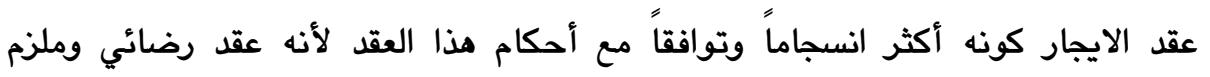

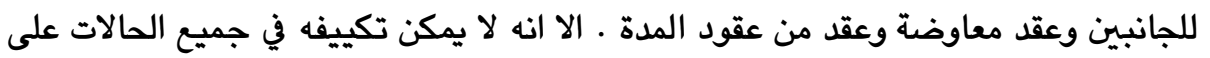
انه عقد ايجار وذلك لوجود حالات يتم فيها الاتفاق على حصول الطبيب الأصيل على نسبة

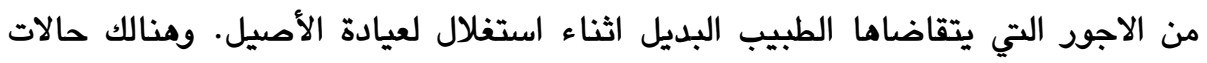

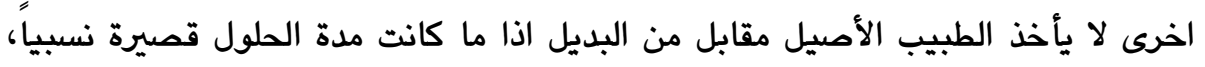

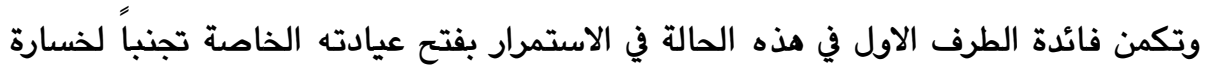
زبائنه فضلا عن ضمان الاستمرار بمتابعة المرضى الذين اعتادوا مراجعته .

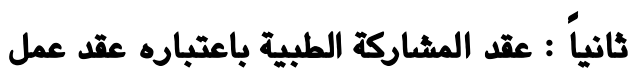
عرفت المشرع العراقي عقد العمل بأنه (عقد يتعهد به احد طرفيه بان يخصص

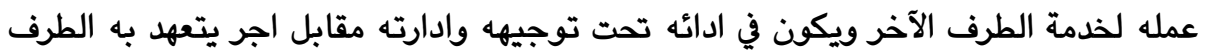
الآخر، ويكون العامل أجيراً خاصاً) (").

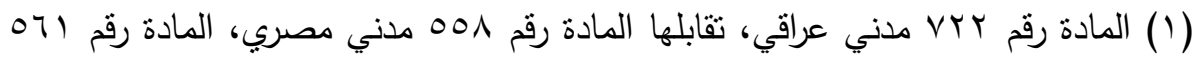

$$
\begin{aligned}
& \text { مدني كويتي، المادة رقم } 701 \text { مدني أردني. }
\end{aligned}
$$

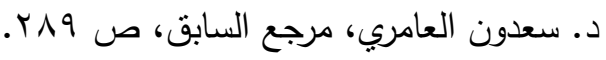

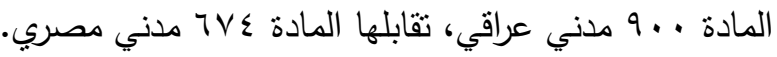


وعرف المشرع الفرنسي عقد إجارة العمل في المادة رقم • IVI من القانون المدني الفرنسي بأنه "ذلك العقد الذي يتعهد فيه أحد أطرافه بعمل شيء لحساب أخر لقاء أجر الجر الجرة متفق عليه بينهما". من هذا يتضح ان عقد العمل هو اتفاق الغرض منه قيام شخص بأداء عمل لحساب شخص آخر وتحت ادارته واشرافه لقاء اجر معين. ومع اقتراب فكرة عقد هد اند

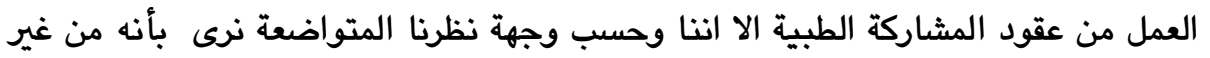

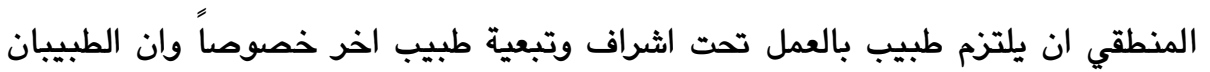
يحملان نفس المؤمل والكفاءة العلمية التي تفرضها معظم القوانين المختصة.

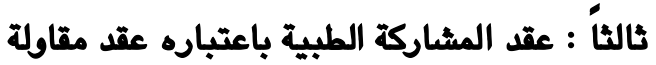

عُرف عقد المقاولة بأنه (عقد به يتعهد أحد الطرفين أن يصنع شيئًا أو يؤدي مغاري

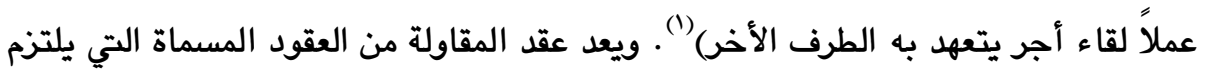

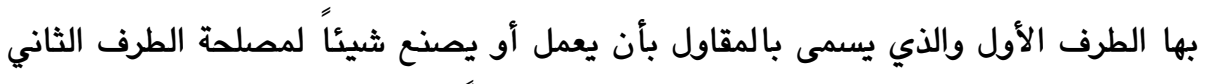

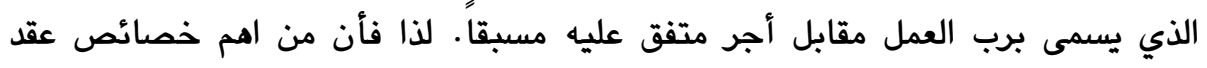

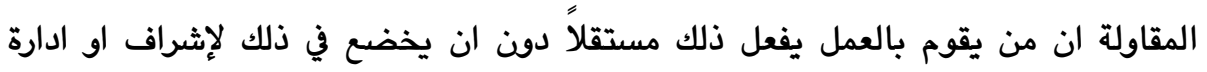

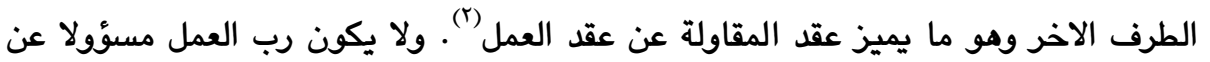
المقاول مسؤولية المتبوع عن أعمال تابعه ("). ويدورنا نعتقد انه لا يمكن اعتبار عقد المشاركة الطبية عقد مقاولة لأن العقود

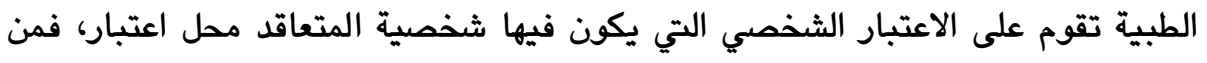

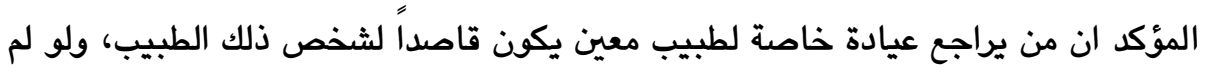

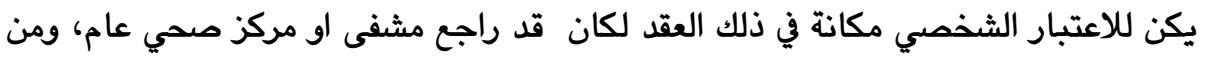
المفروغ منه ان الطبيب البديل لا يمكن ان يتنازل عن هذا الحلول لطبيب آخر يحل محله، وهو ما يسمح به عقد المقاولة تحت تسمية المقاولة من الباطن.

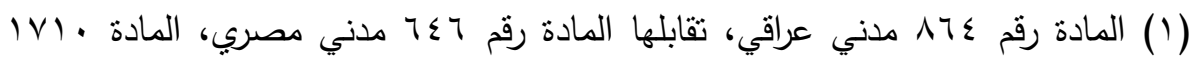
مدني فرنسي.

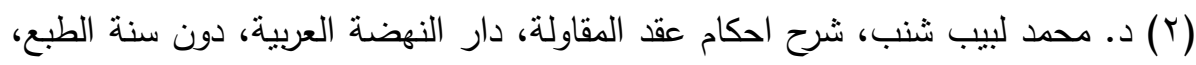
ص . 7 (r) د. محمد جابر الدوري، مسؤولية المقاول والمهندس في مقاولات البناء والمنشآت الثابتة

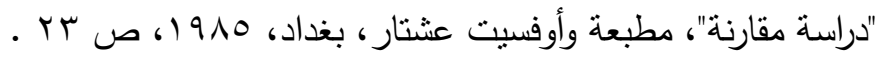


ويعد ان انتهينا من بيان الآراء التي قيلت في تكييف العقود بشكل عام محاولين الوصول الى التكييف القانوني المناسب لعقود المشاركة الطبية فأننا نميل إلى القول بتكييف عقود المشاركة الطبية في معظم حالاتها هي عقود شراكة بين الاطباء يلتزم الطرف الاول فيها بتقديم العيادة وموجوداتها بالسمعة التي تتمتع بها مقابل اعطاء الطرف الثاني جزءاً من الاجور التي يحصل عليها من المرضى الذين يراجعون تلك العيادة ويكون هذا العقد في ظروف استثنائية نصت عليها القوانين ذات الاختصاص، وتبرز صورة الشراكة من جانب الطبيب صاحب العيادة بما يقدمه للطبيب البديل من عيادة وموجوداتها من اثاث واجهزة طبية وتتمثل الشراكة بالريح اذا ما عملت مذه العيادة وقرد عليها الزبائن اما الخسارة فتتمثل بحالة عدم توافد المرضى وتحمل الطبيب الاصيل ايجار العيادة وياقي المصاريف المترتبة عليها من اجور ماء وكهرباء وضرائب، اما بالنسبة للطبيب البديل فيتمثل عنصر المشاركة لديه بالجهد الذي يبذله في استقبال المرض ومعاينتهم والكثف عليهم اما عنصر الخسارة فيتمثل بتواجده بالعيادة واضاعته لوقته استعدادا لاستقبال المرضي الذين سوف يزورون العيادة .

كما قد يكون عقد ايجار يتعهد الطبيب الأصيل بتمكين البديل من استغلال عيادته الخاصة مقابل مبلغ مالي معين يدفعه البديل فضلا عن الالتزامات الاخرى التي يفرضها هذا العقد. وقد يكون هنالك اتفاق على فتح العيادة واستغلالها من قبل الطبيب البديل بدون مقابل مالي يدفع لصاحب العيادة، وتكمن الفائدة للطرف الاول بالاستمرار بفتح عيادته أمام زبائنه .

\section{iأبشئif}

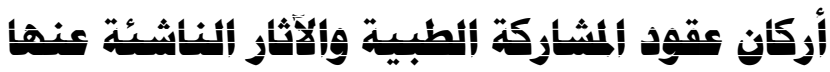

إن من موجبات تكوين العقد توافر أركانه فإذا توافرت أركانه صحيحة قام العقد وإذا تخلفت أركانه بطل العقد ـ فأركان العقد تعد من الشرائط الأساسية لقيامه فهي بمثابة العناصر التي تكونه وهي من الشروط اللازمة لوجوده وهو ما يعرف ببنية العقد (1). وعقود المشاركة الطبية كسائر العقود لابد لقيامها من توافر الاركان الخاصة بالعقد وهي الرضا

(1) د. عبد العزيز المرسي حمود، الحماية المدنية الخاصة لرضاء المشنري في عقود البيع

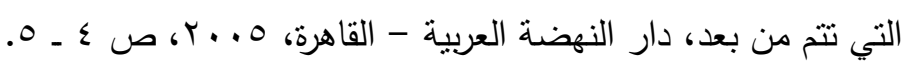


والمحل والسبب، واذا ما قامت هذه العقود فإنها سوف ترتب اثاراً على اطرافها وهو ما سنحاول ان نبينه من خلال تقسيم هذا المبحث على مطلبين نتناول في المطلب الأول اركان عقود المشاركة الطبية أما المطلب الثاني فسوف نتناول فيه الاثار القانونية لعقود المشاركة الطبية وكما يأتي:

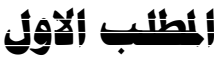

\section{أركان عقمد ألشاركة أنطبية}

الأركان جمع ركن والركن في اصطلاح علماء الأصول ما يتوقف عليه وجود الشيء وكان غير داخل في حقيقته، وأركانه هي أجزاؤه التي يتألف منها ويتحقق بهاء لاهن

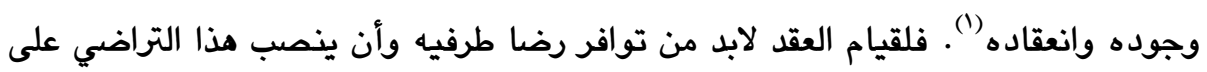

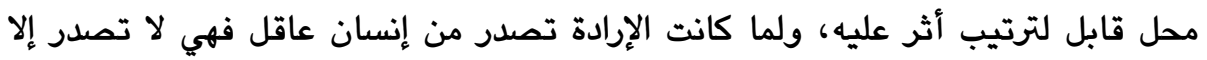
لغاية أو دافع لهذا كان السبب ركناً آخر من أركان العقد.

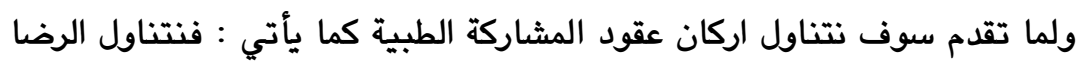

باعتباره الركن الاول بينما نتناول المحل باعتباره الركن الثاني ونتناول السبب باعتباره

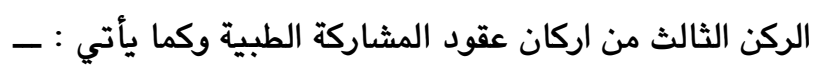

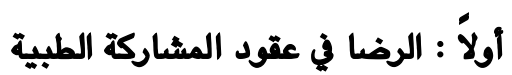

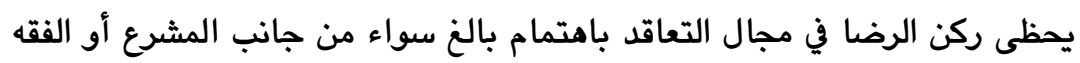
والقضاء ويرجع ذلك لكون الإرادة جوهر العقد وأكثر موضوعاته حاجة إلى البيان

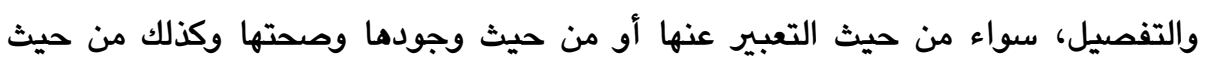

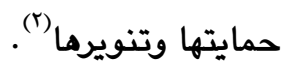

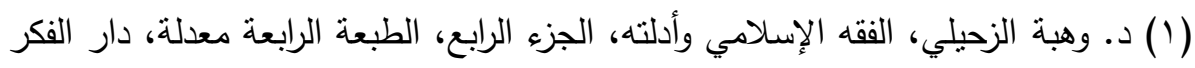

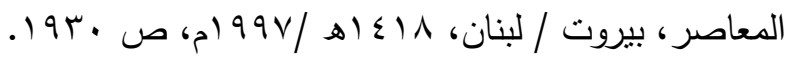

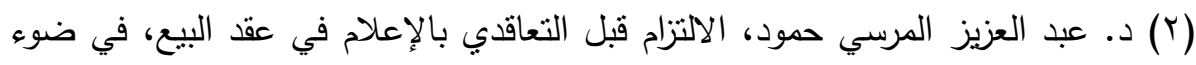

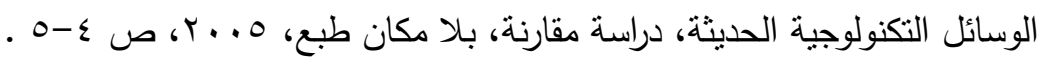


والرضا أو التراضي هو"اتفاق إرادتين على إحداث اثر قانوني"(1). فالرضا يمثل

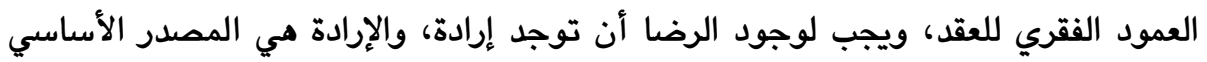

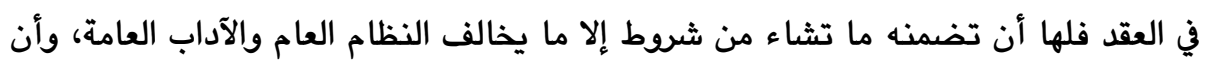
تتجه هذه الإرادة إلى أحداث أثر قانوني معين، وأن يعبر عن هذه الإرادة بإحدى الطرائق المعروفة قانوناً .

فضلا عن ذلك يجب أن تتجه الإرادة إلى علم من وجهت إليه لكي تكون منتجة لآثارها القانونية. وإن مجرد وجود التراضي لا يكفي لانعقاد العقد صحيحاً ونافذاً مرتباً

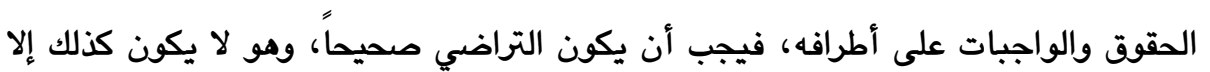

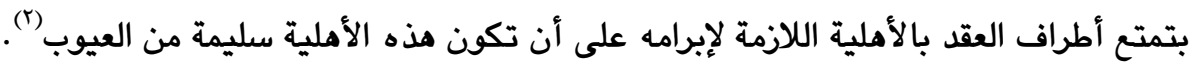

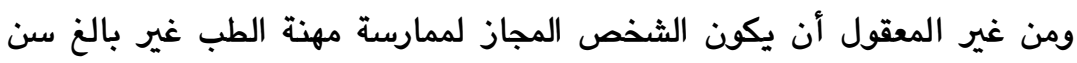
الرشد او يعتريه عارض من عوارض الأملية فمهنة الطب قاصرة على من تتوفر فيه شروط هذه المهنة المنصوص عليها في جميع التشريعات الخاصة بها والتي سبق ذكرها والتي يمكن اجمالها في اشتراط الحصول على المؤهل العلمي المطلوب والتمتع بالجنسية والقيد في جدول النقابات المختصة . ولما كانت العلاقة القائمة بين الطبيب الأصيل صاحب العيادة الخاصة والطبيب

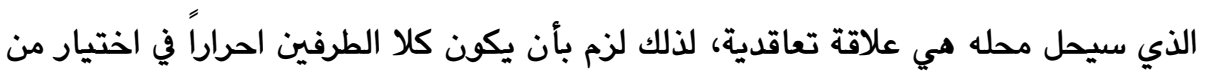

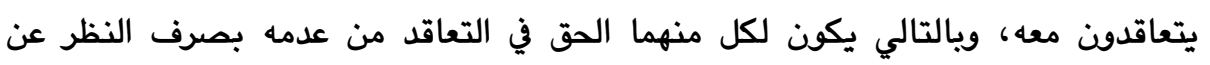

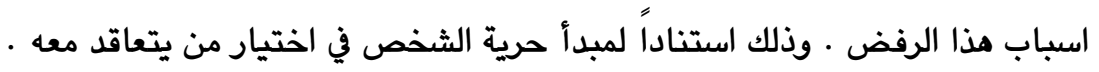

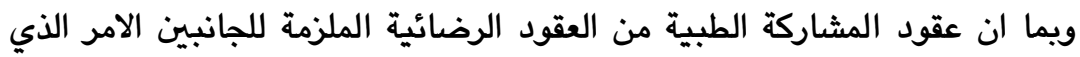

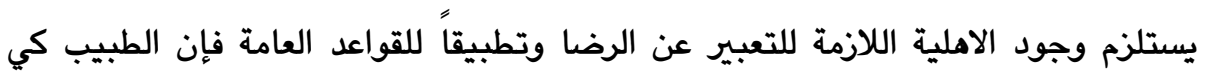
يباشر مهنته سواء في القطاع الخاص ام في القطاع العام يجب ان يكون متمتعاً بالأهلية

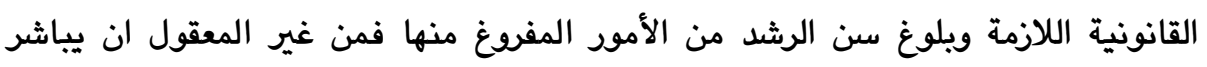

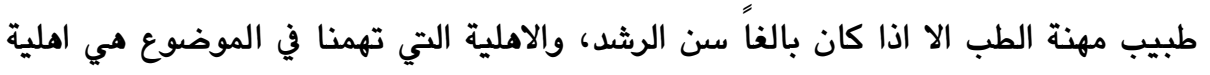

(1) د. عبد المجيد الحكيم، مصادر الالنتام الإرادية وغير الإرادية، الطبعة الثانية، دار

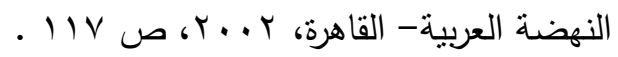

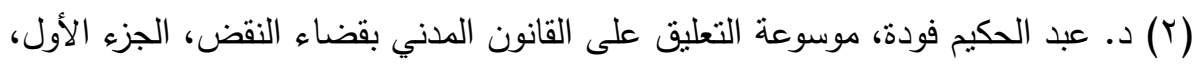

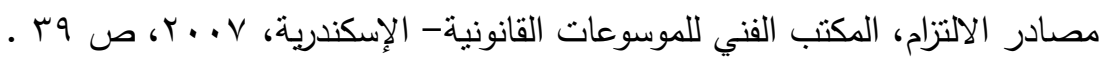


الشخص بمباشرة العمل الطبي وهي استيفاؤه الشروط القانونية اللازمة لمباشرة مهنة الطب المتمثلة بالحصول على المؤهل العلمي المطلوب والتقييد في سجلات النقابات والجنسية بالنسبة للعراقيين او قبول الانتماء للنقابة على اساس المعاملة بالنسبة لغير العراقيين ـ فتنص المادة r من قانون نقابة الاطباء العراقيين مثلا على انه (لا يجوز للطبيب ممارسة المهنة في العراق إلا بعد انتمائه إلى النقابة وحصوله على شهاه الهادة التسجيل

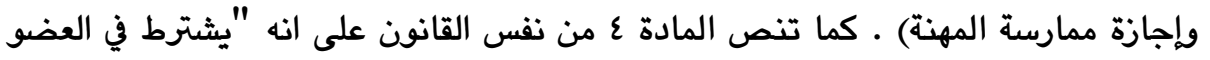

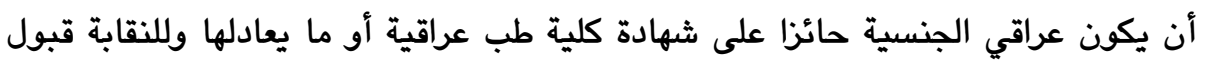
انتماء الأطباء العرب والأجانب الذين لم يحرموا من حق الممارسة في بلادهم بسبب أساءتهم للمهنة ومن تعامل بلادهم العراق بالمثل أو الذين قد ارتبطوا مع إحدى الجهات الوطنية في الوني

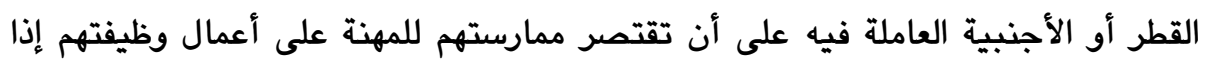

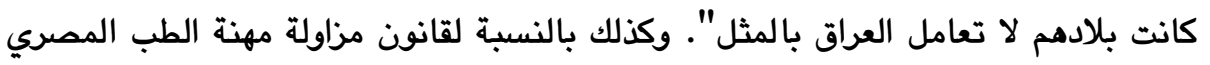
رقم اع لسنة 1901 اذ تنص المادة ا منه على انه "لا يجوز ..... بوجه عام مزاولة مهنة الطب بأية صفة كانت إلا إذا كان مصريا أو كان من بلد تجيز قوانينه للمصريين مزاولة المانه

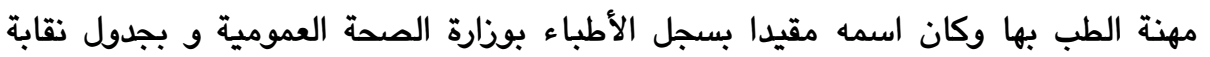

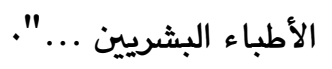

وكذلك الحال بالنسبة لقانون الصحة العامة الفرنسي رقم •r لسنة ع... ف فتنص المادة rT في ترخيص المهن الصحية على انه "يحظر الترخيص لمزاولة أي مهنة صحية،

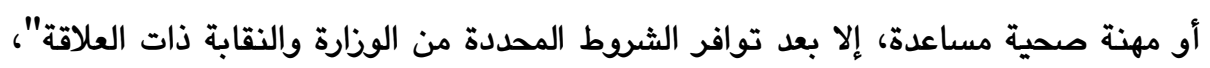
كما تنص المادة بامنه على انه "يحظر مزاولة أية مهنة صحية، أو مهنة صحية مساعدة، إلا بعد الحصول على الترخيص" ثانياً : المحل في عقود المشاركة الطبية يعرف المحل بأنه "العملية القانونية التي تراضى المتعاقدان على تحقيقها ويشرط أن لا تكون مخالفة للقواعد العامة للعدالة والآداب العامة"|(1).

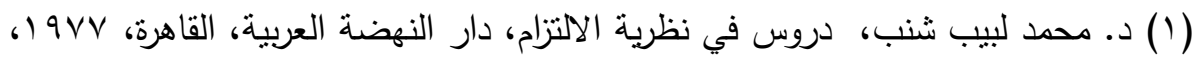
ص 
وهو الركن الثاني في العقد، فحتى ينعقد العقد صحيحاً لابد أن يكون له محل قابل لحكمه (1).

ومحل عقود المشاركة الطبية بالنسبة للطرف الاول وهو صاحب العيادة الخاصة

تمكين الطرف الثاني من استغلال عيادته الخاصة فضلا عن الحصول على الموافقات الاصولية لهذا الحلول، أما المحل بالنسبة للطرف الثاني هو اداء المبلغ المالي المتفق عليه مع الطرف الاول واحترام اصول وقواعد المهنة والمحافظة على سمعة وموجودات العيادة . ثالثاً : السبب في عقود المشاركة الطبية يعرف السبب بأنه "الغرض المباشر الذي يقصد الملتزم الوصول إليه من وراء التزامه" (r) . ويتصل السبب اتصالا وثيقاً بالإرادة، ولكنه ليس نفس الإرادة بل انه الغرض المباشر الذي تتجه إليه الإرادة، فيوجد السبب حيث توجد الإرادة(r). فيجب أن يكون لكل

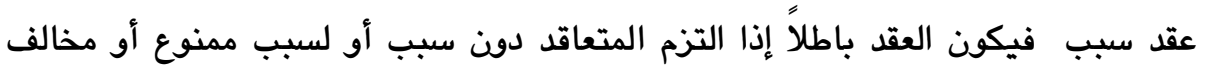

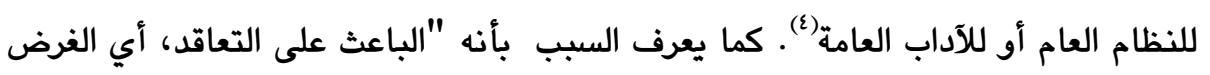

(1) تتص الفقرة الأولى من المادة رقم سبا من القانون المدني العراقي على أن (العقد الصحيح هو العقد المشروع ذاتاً ووصفاً بان يكون صادراً من أهله مضافاً إلى محل قابل لحكمه وله سبب مشروع وأوصافه صحيحة سالمة من الخلل). (Y) تعريف كابيتان للسبب، نقلا عن • عبد الحميد عمر وشاحي، نظرية الالتزام في القانون المدني، مجموعة المحاضرات التي ألقاها على طلبة كلية الحقوق العراقية سنة . ـ9 اــ

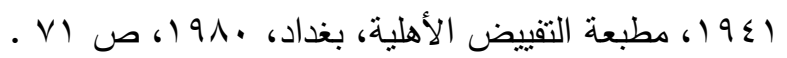
(ץ) د. فريد فتيان، التعبير عن الإرادة في الفقه الإسلامي والفقه المدني، معهد البحوث

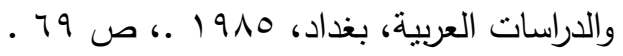
(ع) تتص الفقرة الأولى من المادة رقم بسا من القانون المدني العراقي على أنه (يكون العقد باطلاً إذا التزم المتعاقدون دون سبب أو لسبب ممنوع قانونا ومخالف للنظام العام أو من 
البعيد أو غير المباشر الذي جعل الملتزم يتعاقد"(1). وهو ما جاءت به النظرية الحديثة للسبب .

ونعتقد ان السبب في عقود المشاركة الطبية يتمثل بالغرض البعيد او الباعث

الدافع الذي قصده كلا الطرفين في العقد، والسبب بالنسبة للطرف الاول يتمثل بالاستمرار

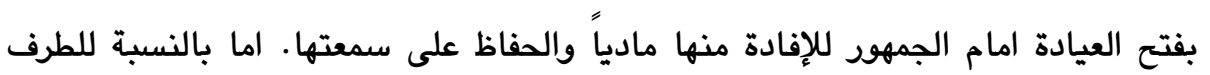
الثاني فيتمثل السبب بالحصول على الشهرة والمنفعة المادية من جراء استغلاله العيادة والعمل بها، كون الطرف الثاني وهو الطبيب الذي حل محل الطبيب الأصيل اقل شهرة وزبائناً من الطرف الاول.

\section{|}

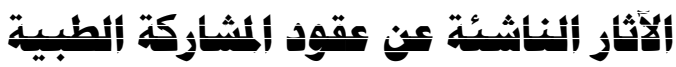

بعد قيام عقود المشاركة الطبية بتوافر أركانها الثلاث المتمثلة بالرضا والمحل والسبب وصدود الإرادة ممن هو أهل لها وعدم تعرض أطرافها لعارض من عوارض الأهلية

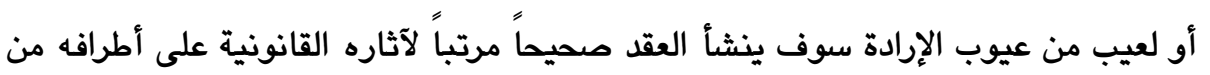

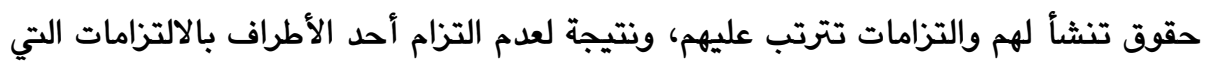
يفرضها عليه العقد تنهض مسؤوليته بجميع أشكالها المدنية منها والجزائية عند توافر أركانها.

عليه ولما تقدم سوف نقسم هذا المطلب على فرعين نخصص الأول لبيان

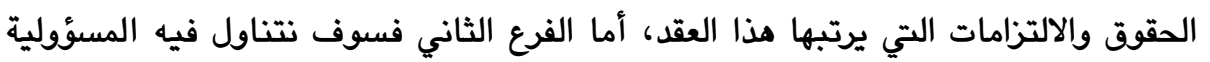

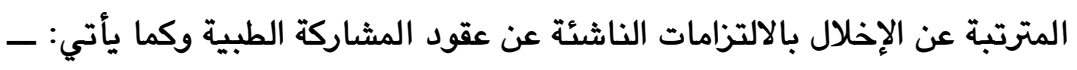

(1) د. عبد المجيد الحكيم، عبد الباقي البكري، محمد طه البشير، الوجيز في نظرية الالتزام،

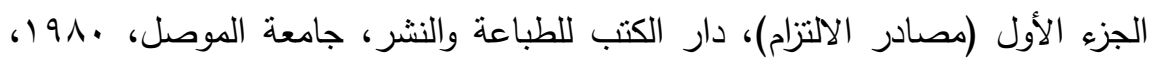
ص 1.1. 


\section{jg:ili

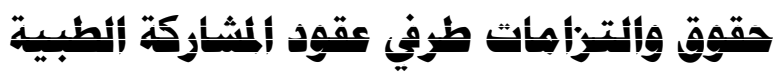

لعل من الواجب ذكره أثناء الكلام على الآثار القانونية التي تترتب على عقود

المشاركة الطبية ذكر الالتزامات التي يرتبها هذا العقد على طرفيه والحقوق التي يعترف لهم

بها، فعقود المشاركة الطبية ترتب التزامات متقابلة على طرفيه، فيعطى الطبيب صاحب العيادة الخاصة وهو الطرف الأول للعقد حقوق كما يرتب عليه التزامات، وكذلك هو الحال بالنسبة للطرف الثاني في العقد وهو الطبيب الذي يحل محله. فمن أهم الالتزامات الذي تفرضها عقود المشاركة الطبية على الطرف الأول هو الالتزام بتمكين الطرف الثاني من استغلال العيادة الطبية، كما يترتب عليه التزام بإعلام الجهات ذات الاختصاص في حالة تغيبه عن العيادة وتكليف زميل بإداراتها فمثلا تنص المادة Vع من قانون ممارسة مهنة الطب المغربي على انه "ي حالة غياب مؤقت يمكن لطبيب ان يطلب من رئيس المجلس الجهوي للهيئة بأن ينيب عنه أحد زملائه ......."، كما تنص المادة ^^ من الدستور الطبي الأردني على انه "لا يجوز أن تدار عيادة طبيب في حالة غيابه عنها خارج .............. إلا بموافقة مجلس النقابة". ومقابل هذه الالتزامات فأن الطبيب البديل تترتب عليه التزامات منها تسديد المقابل المالي لاستغلاله لعيادة الطرف الاول، والحفاظ على موجودات العيادة من اجهزة طبية واثاث، ومسؤولية الحفاظ على سمعة العيادة، وتجنب منافسة الطبيب الأصيل عند انتهاء مدة العقد، كما يقع عليه التزام اعلام المريض بأنه ليس بالطبيب الأصيل صاحب العيادة وانه البديل عنه ومذا الحلول لا يتعارض مبدئيا مع قواعد مهنة الطب واخلاقياتها متى كان الطبيب الجديد على قدرة وكفاءة تتناسب مع كفاءة الطبيب الأصيل وهو تكريس لمبدأ حرية المريض في اختيار طبيبه (') ويالنظر لكون هذه العقود من العقود الملزمة للجانبين فأن ما يعد حقاً بالنسبة لطرف فأنه يعد التزاماً على الطرف الآخر.

(1) زينة غانم يونس العبيدي، إرادة المريض في العقد الطبي (دراسة مقارنة)، أطروحة دكتوراه، كلية القانون جامعة الموصل، 0 . . Y، ص ب V. 


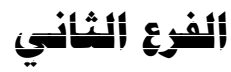

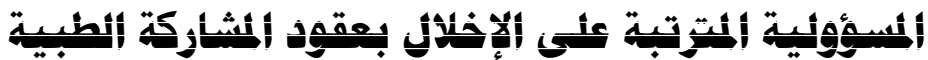

يحكم القانون سلوك الأفراد في المجتمع من خلال تنظيم الروابط والعلاقات فيما بينهم وذلك بتنظيم حقوقهم وواجباتهم المتبادلة، فكل حق يقابله التزام وكل إخلال بالالتزام يرتب المسؤولية على الطرف المخل. والمسؤولية لغة: هي "التبعة" (1).

أما المسؤولية اصطلاحاً : فهي "الموجب (الالتزام) الذي يتحمله الشخص نتيجة

لأفعاله أو لأفعال الآخرين المسؤول عنهم أو الأشياء التي يملكها أو يستعملها" (كأ.

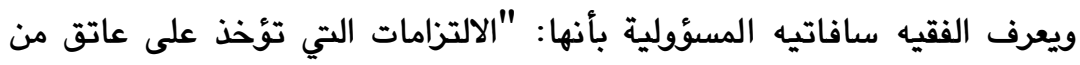

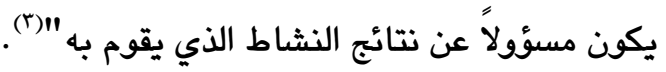

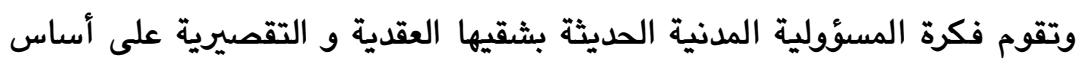

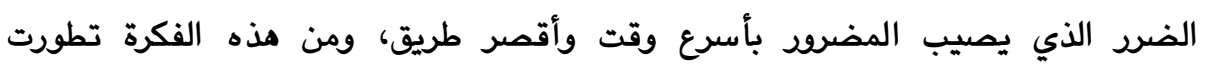

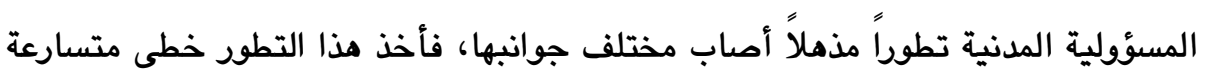

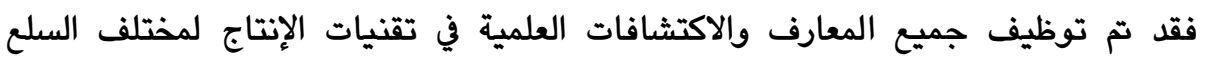
والخدمات مما أدى إلى ظهور عقود جديدة لم يكن لها وجود قبل وقت قصير مما يدفع

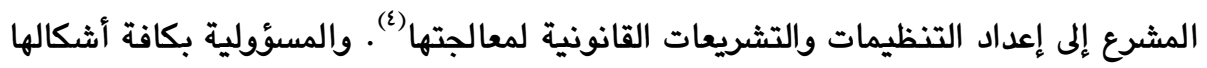
يتطلب لنهوضها توافر ثلاثة أركان وهي الخطأ والضرد والعلاقة السببية.

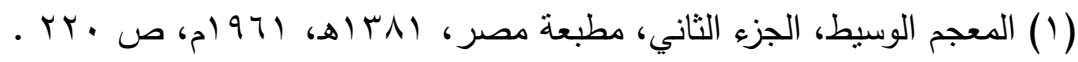

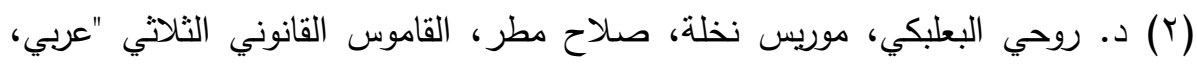

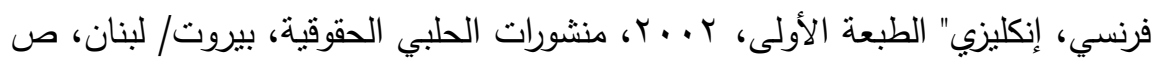

(T) د. جبار طه، إقامة المسؤولية على العمل غير المشروع على عنصر الضرر، منشورات

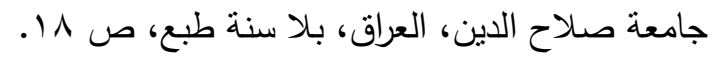

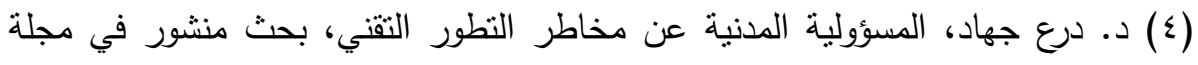

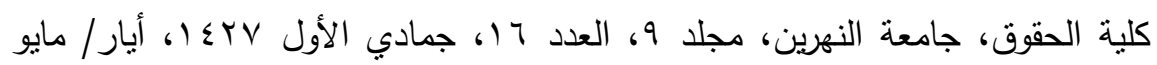

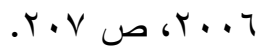


وتنشأ المسؤولية في عقود المشاركة الطبية نتيجة الإخلال بالالتزامات التي يفرضها القانون والعلاقة العقدية ومبدأ حسن النية في تنفيذ العقود فضلا عن الأخلاق والمبادئ العامة، فتترتب المسؤولية المدنية بشقيها العقدية و التقصيرية فضلا عن المسؤولية الجزائية على طرفي العقد نتيجة للإخلال بالالتزامات التي يفرضها العقد والقانون. ولغرض الابتعاد عن القواعد العامة التقليدية في موضوع المسؤولية التي تتناول مسؤولية طرفي العقد عن الإخلال بالالتزامات، سوف نناقش على من تقع هذه المسؤولية في

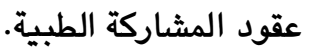
فكما بينا من خلال بحثنا هذا بأن طرفي العقد هما اطباء يمارسون مهنة الطب فقد

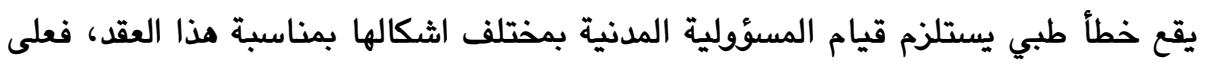
من تقع هذه المسؤولية فهل تقع على الطبيب صاحب العيادة كون الفعل قد وقع بعيادته ويسبب اشخاص تقع عليه مسؤولية اختيارهم ام تقع على الطبيب الذي حل محل الطبيب

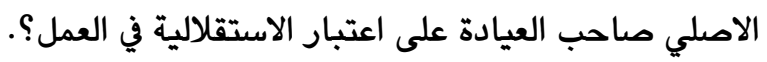
والإجابة على هذا السؤال تختلف باختلاف التكييف القانوني الذي يعتمد، فإذا اعتبر العقد الذي ثم بين الطرفين عقد إيجار فيتحمل الطبيب الذي حل محل الطبيب الأصيل في العيادة تلك المسؤولية على اعتبار الطبيب البديل متمتع بالاستقلال في عمله. كذلك هو الحال اذا ما تم تكييف العقد على انه عقد مشاركة كون الطبيب الأصيل مشترك بعيادته فقط اما الطبيب البديل هو من يقوم بالعمل الفني المرتبط بمهنة الطب.

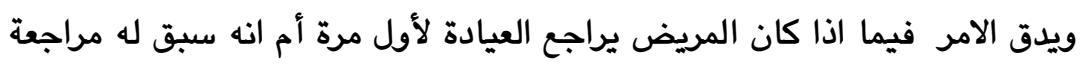

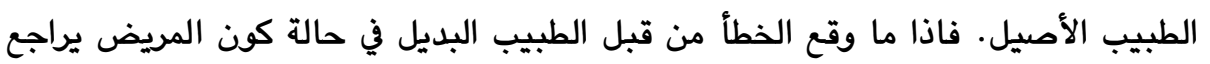

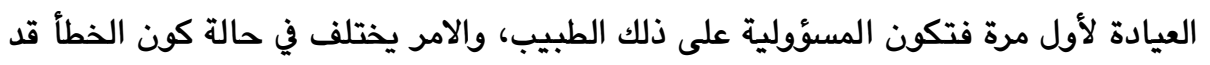
وقع اثناء علاج لمريض سبق له مراجعة الطبيب الأصيل فأوكل الطبيب الأصيل مهمة

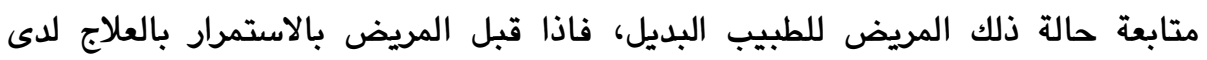

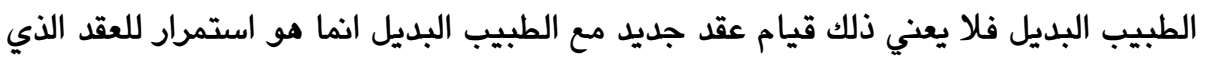

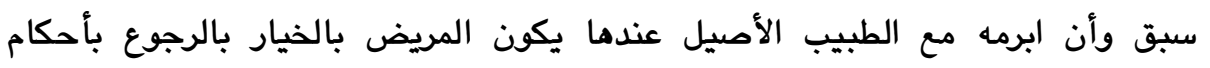

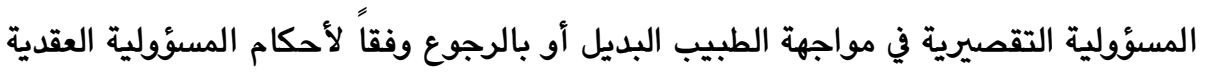




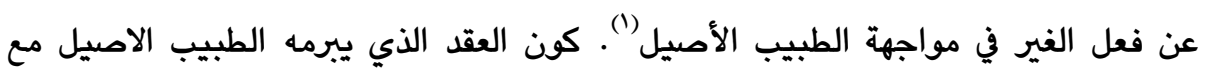
البديل لا يفسخ العقد الاصلي الذي ابرمه الطبيب الاصيل مع المريض بل هول هو وسيلة

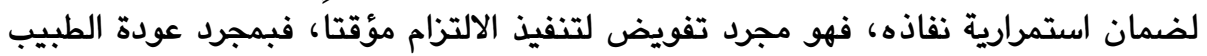
الاصيل تنتهي مهمة البديل (r)

والسؤال الذي يطرح نفسه عن حكم المسؤولية الناجمة وما طبيعتها القانونية في حالة كون العقد القائم غير صحيح (الطبيب الأصيل صاحب العيادة لم ييلغ الجهات الرقابية بحلول طبيب محله في العيادة الخاصة به ولم يستحصل الموافقات الاصولية لذلك)؟. فإذا ما أقدم طبيب على احلال طبيب محله في عيادته الخاصة وهو غير قادر على أن يستوفي الشروط اللازمة لهذا الحلول (الحصول على اذن من الجهات المختصة) كان

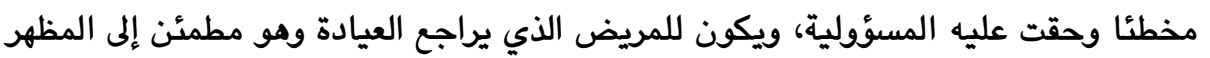

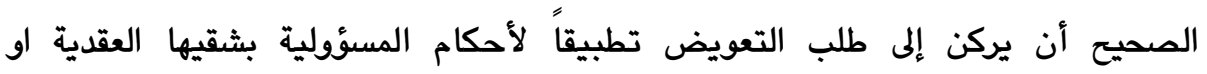

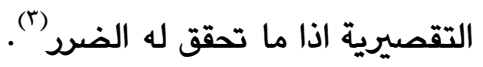

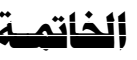

في ختام هذه الدراسة التي كرسناها لموضوع عقود المشاركة الطبية فإننا قد توصلنا الى مجموعة من النتائج والتوصيات والتي نوردها كما يأتي : أولاً النتائج : I. ان المشرع العراقي لم ينظم هذا النوع من العقود، بل انه لم يحدد حتى الشروط اللازمة لحلول طبيب محل طبيب اخر في عيادته الخاصة كما فعلت معظم التشريعات المختصة بذلك · بل انه تناول الموضوع بشكل خجول في الفقرة الخامسة من المادة rA من قانون

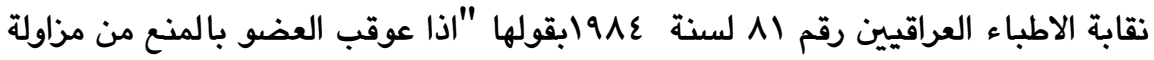
المهنة فلا يجوز ان يحل في عيادته زميل اخر مدة المنع".

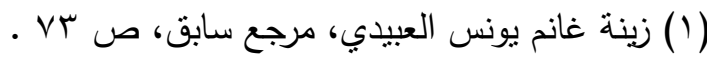

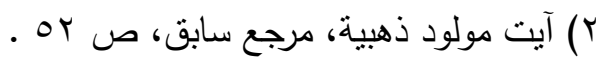

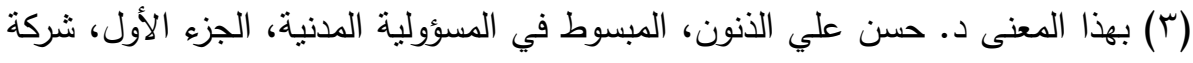

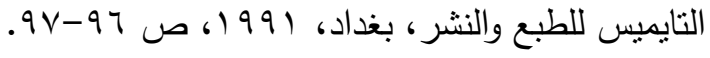


r. إن عقود المشاركة الطبية من العقود حديثة النشأة والتي تخضع للقواعد العامة، وهي عقود رضائية تنعقد باتفاق الطرفين كما انها من عقود المعاوضة التي يأخذ كلا طرفيها مقابلا لما يعطيه، وهي كذلك من العقود المستمرة التي يكون الزمن عنصراً جوهرياً فيها.

r. ان عقود المشاركة الطبية في معظم الحالات هي عقود شراكة لوجود اتفاق على حصول الطبيب الأصيل على نسبة من الأجور التي يتقاضاها الطبيب البديل اثناء استغلال

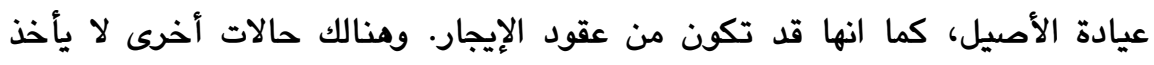

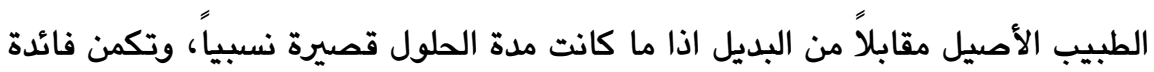

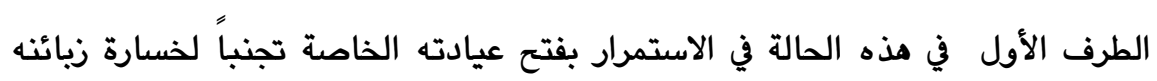
فضلا عن ضمان الاستمرار بمتابعة المرضى الذين اعتادوا مراجعته.

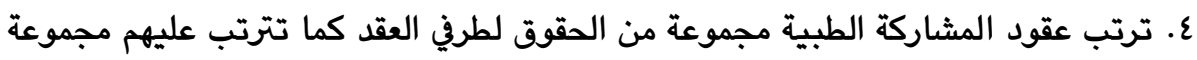
من الالتزامات. ๑. تتترتب على طرفي عقود المشاركة الطبية المسؤولية من جراء عدم الالتزام بما يقتضيه القانون والعقد. فتتحقق المسؤولية التقصيرية بحق الطبيب البديل اذا ما كيف العقد مند على انه عقد مشاركة او عقد إيجار، وتختلف مسؤولية طرفي العقد باختلاف حالة المريض المراجع للعيادة فتتحقق مسؤولية الطبيب البديل إذا ما كان المريض يراجع

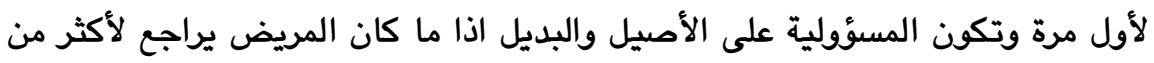
مرة مع رضائه بأن يستمر العلاج لدى الطبيب البديل. ثانياً : التوصيات

ندعو المشرع العراقي إلى تنظيم موضوع حلول الأطباء محل بعضهم البعض بنص خاص وفق شروط معينة وكما فعلت التشريعات المقارنة . محددا فيه ضرورة : الحصول على موافقة نقابة الأطباء العراقية، تسجيل الطبيب البديل في سجلات فئلات النقابة وموافقتها، شهادة وخبرة الطبيب البديل، مدة الحلول. ندعو المشرع كذلك الى صياغة قواعد قانونية تلزم الأطباء البدلاء بإعلام

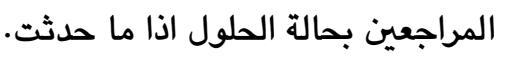


كما ندعو الى تنظيم هذا النوع من العقود بقالب قانوني خاص لتسهيل تفسير

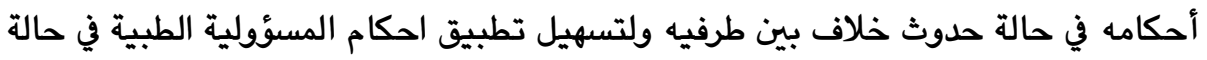
حصول الخطأ الطبي.

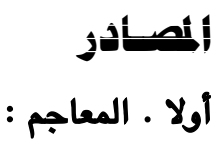

ا. العلامة أبن منظور، لسان العرب، الجزء العاشر، الطبعة الرابعة، دار صادر للطباعة

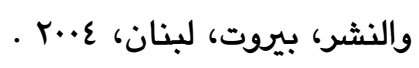

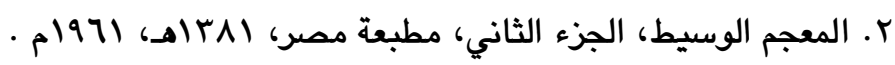

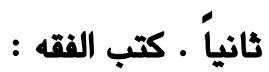

r. د. وهبة الزحيلي، الفقه الإسلامي وأدلته، الجزء الرابع، الطبعة الرابعة معدلة، دار الفكر

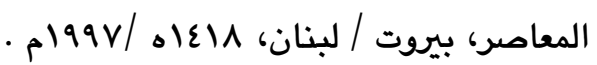

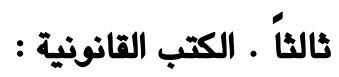

ع. د. جبار طه، إقامة المسؤولية على العمل غير المشروع على عنصر الضرر، منشورات

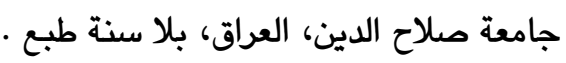
๑. د. حسن علي الذنون، النظرية العامة للالتزام، الجزء الأول ، مصادر الالتزام، بغداد،

$$
19 \vee 7 .
$$

7. د. حسن علي الذنون، المبسوط في المسؤولية المدنية، الجزء الأول، شركة التايميس

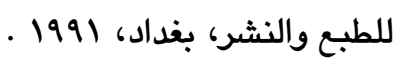

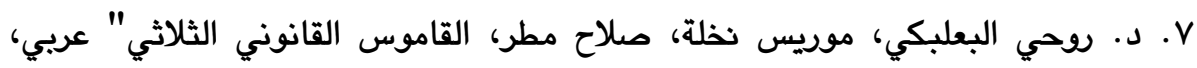

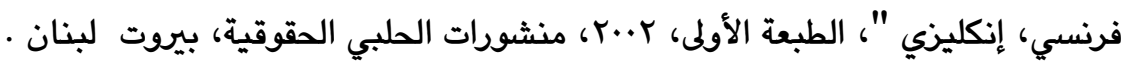

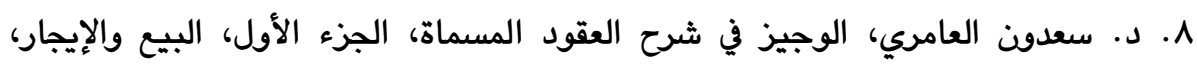

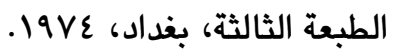

9. د. عبد الحكيم فودة، موسوعة التعليق على القانون المدني بقضاء النقض، الجزء

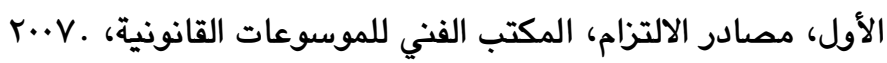
•.

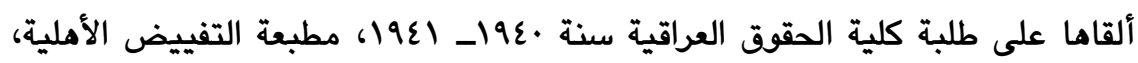

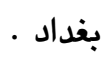


II. د. عبد الرزاق أحمد السنهوري، الوسيط في شرح القانون المدني، الجزء الرابع، العقود

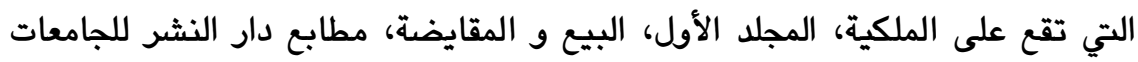
المصرية، .197.

rا. د. عبد الرذاق أحمد السنهوري، الوجيز في شرح القانون المدني، الجزء الأول، نظرية الالتزام بوجه عام، دار النهضة العربية، القاهرة، 1977. rا. د. عبد العزيز المرسي حمود، الحماية المدنية الخاصة لرضاء المشتري في عقود البيع دراهيه

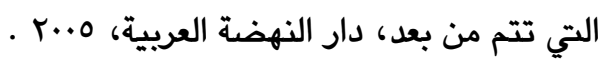

عا. د. عبد العزيز المرسي حمود، الالتزام قبل التعاقدي بالإعلام في عقد البيع، في ضوء

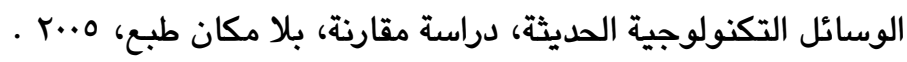

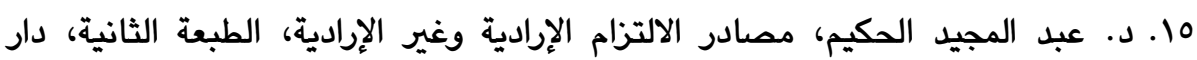

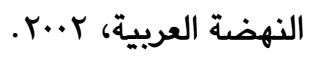

17 ا. د. عبد المجيد الحكيم، عبد الباقي البكري، محمد طه البشير، الوجيز في نظرية

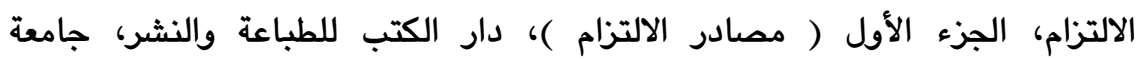

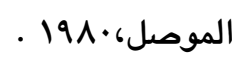

IV د. د. عصمت عبد المجيد بكر، نظرية العقد في الفقه الإسلامي " دراسة مقارنة مع الفقه

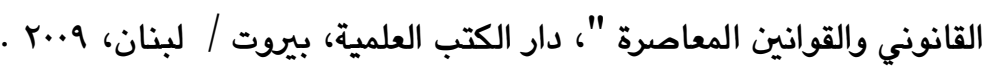

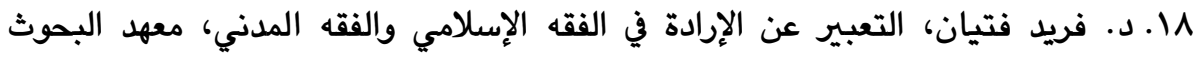
والدراسات العربية، بغداد، 1910 .

19. د. محمد جابر الدوري، مسؤولية المقاول والمهندس في مقاولات البناء والمنشآت الثابتة " دراسة مقارنة "، مطبعة وأوفسيت عشتار، بغداد، 1910.

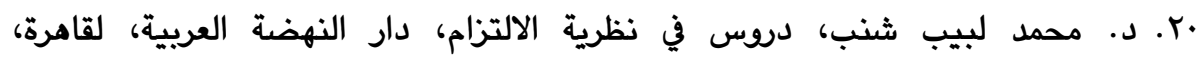
$.19 \mathrm{~V}$

I. M. د. محمد لبيب شنب، شرح أحكام عقد المقاولة، دار النهضة العربية، دون سنة الطبع.

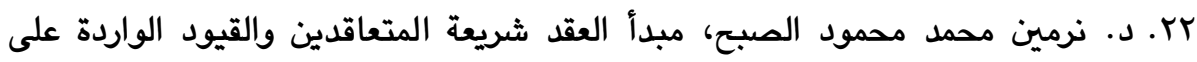

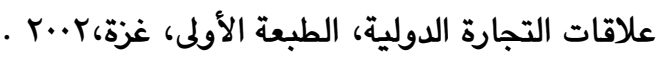


رابعاً . الرساثل الجامعية :

rr. زينة غانم يونس العبيدي، إرادة المريض في العقد الطبي (دراسة مقارنة)، أطروحة دكتوراه، كلية القانون جامعة الموصل، .....

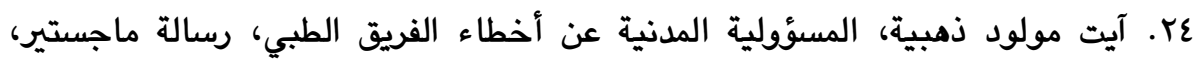

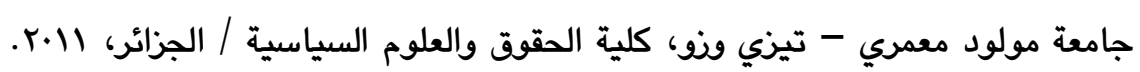

$$
\text { متاحة على شبكة المعلومات العالمية : }
$$

http://www.droitetentreprise.com

\section{خامساً . البحوث القانونية :}

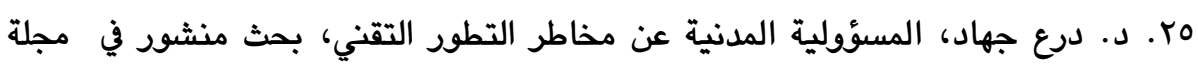

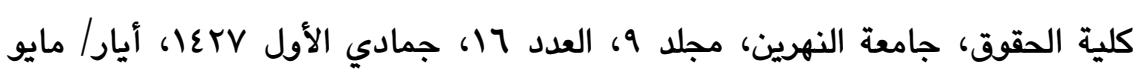

7. . د. محمد سليمان الأحمد، أهمية الفرق بين التكييف القانوني والطبيعة القانونية في تحديد نطاق تطبيق القانون المختص، بحث منشور في مجلة الرافدين للحقوق، تصدر المديك

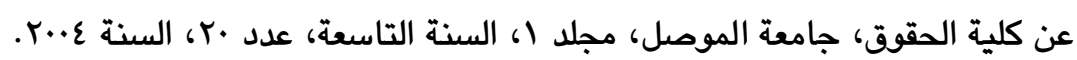
سادساً . القوانين :

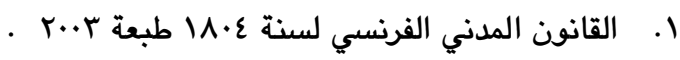

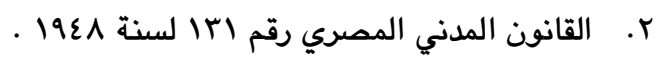

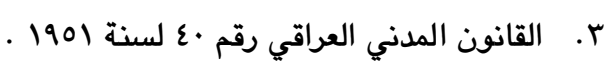

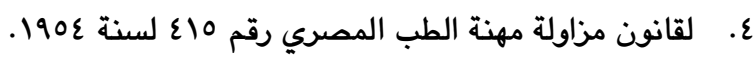

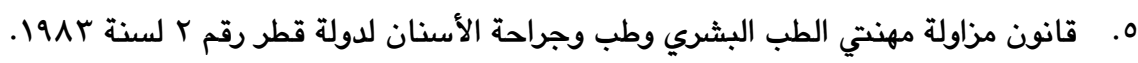

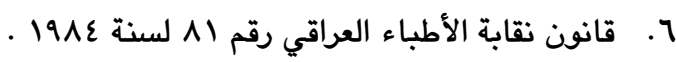

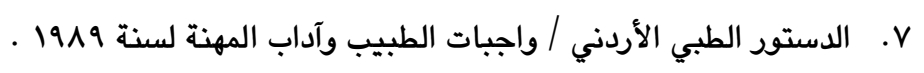

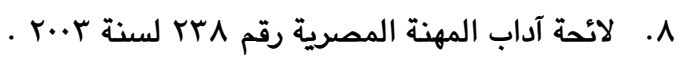

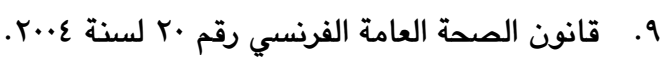

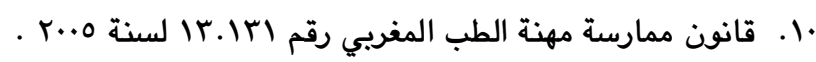

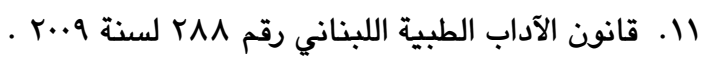

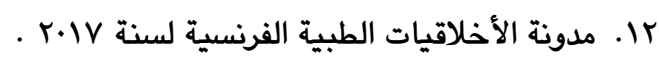

